Check for updates

Cite this: RSC Adv., 2019, 9, 12232

Received 13th February 2019

Accepted 7th April 2019

DOI: 10.1039/c9ra01133a

rsc.li/rsc-advances

\section{Mesoporous bioactive glass nanoparticles doped with magnesium: drug delivery and acellular in vitro bioactivity}

\begin{abstract}
Zakaria Tabia, $^{\text {ab }}$ Khalil El Mabrouk, (D) *a Meriame Bricha ${ }^{a}$ and Khalid Nouneh ${ }^{b}$
The effects of the magnesium doping of binary glass ( $\mathrm{Si}-\mathrm{Ca}$ ) on particle texture, on the biomineralization process in simulated body fluid (SBF) as well as on drug loading and release were examined. For this purpose, magnesium-doped binary bioglass nanoparticles $\left(85 \mathrm{SiO}_{2}-(15-x) \mathrm{CaO}-x \mathrm{MgO}\right.$, with $x=1,3,5$ and $10 \mathrm{~mol} \%$ ) were prepared by a base catalysed sol-gel method. $\mathrm{N}_{2}$ adsorption isotherm analysis showed an enhancement in specific surface area as the $\mathrm{Mg}$ molar fraction increased. In addition, the FTIR spectra of the samples after soaking in SBF for various periods of time confirmed the presence of new chemical bonds related to the apatite phase, as was also confirmed by SEM observations. XRD patterns of the samples after soaking revealed that the crystallization to form a more stable apatite-like phase was hindered with increasing magnesium content in the glass composition. Furthermore, it was proved that the kinetics of drug release improved with increasing magnesium content. The porosity and the specific surface area were found to be responsible for this improvement.
\end{abstract}

\section{Introduction}

In the last two decades, an increasing demand for bone substitutes has been observed, due to the increase of bone diseases, traumatic injuries, and aging of the population. To fulfill this urging demand, tissue engineering and biomaterials science have been intensively studied. ${ }^{1}$ Among all biomaterials, ceramics and bioactive glasses have been shown to be promising candidates for bone regeneration applications. These inorganic materials are considered attractive, essentially because of their capability to bone-bond. After their implantation in a bone defect, they develop a carbonated hydroxyl apatite-like layer (CHA) on their surface, similar to the mineral phase of bone. This newly formed layer provides adhesion and strong bonding with bone tissues. Moreover, and based on various in vivo studies, bioactive glasses have shown superior biological properties compared with other bioceramics, ${ }^{2-4}$ due to their distinct features and properties.

Since the development of the first composition by Hench et al. in $1969,{ }^{5}$ bioactive glasses have gained a lot of attention over the years. Many studies have been carried out to develop new formulations and compositions of these bioactive materials for use in the tissue engineering field. Until now, three bioactive glass generations can be distinguished. ${ }^{6}$ The first

${ }^{a}$ Euromed Research Center, Euromed Engineering Faculty, Euromed University of Fes, Eco-Campus, Meknes Road, Campus UEMF, BP51, 30 030, Fes, Morocco. E-mail: $k$. elmabrouk@ueuromed.org; Fax: +212 537716 040; Tel: +212 662054920

${ }^{b}$ Laboratory of Physics of Condensed Matter (LPMC), Department of Physics, Ibn Tofail University, Kenitra, Morocco generation corresponds to bioactive glasses prepared by the melt-quench method, which began with the composition reported by Hench and et al. in the $\mathrm{Na}_{2} \mathrm{O}-\mathrm{CaO}-\mathrm{P}_{2} \mathrm{O}_{5}-\mathrm{SiO}_{2}$ system, known as the $45 \mathrm{~S} 5 .{ }^{5}$ Then, in 1991, Li et al. introduced the second generation by using sol-gel chemistry to produce glasses with superior textural properties. ${ }^{7}$ The sol-gel method is an alternative way to prepare bioactive glasses at lower temperature. Moreover, it provides glasses with high porosity, homogeneity and purity, which are essential elements for enhancing the bioactive response. ${ }^{6}$ The superior textural properties allow the surface interaction with biological fluids to be increased, thus accelerating the kinetics of formation of the apatite layer both in vitro and in vivo. ${ }^{8}$ The third and most recent generation, which was initiated in 2004, is based on the addition of structure directing agents (surfactants) in the sol-gel chemistry to further increase the textural properties and thus accelerate the bioactive response mechanisms. ${ }^{9}$ These materials, referred to as template glasses, are characterized by an ordered structure of mesopores, and they show superior apatite forming ability over conventional sol-gel glasses. Their wellorganized mesoporous structure and increased textural properties aid rapid ion exchange between the biological surrounding medium and the glass surface, which leads to fast supersaturation and rapid precipitation of the new apatite layer on their surface. ${ }^{6,9}$ Incorporation of structure directing agents has given bioactive glasses other potential fields of application as systematic delivery systems and implantable local-delivery devices, and it has enabled them to be multifunctional materials. ${ }^{2,6}$ In contrast to the melt-quenched method, sol-gel permits the synthesis of bioactive glasses in less complex 
composition systems and with high silica contents. ${ }^{10}$ Martinez et al. investigated the bioactivity of sol-gel derived binary glasses in the system $\mathrm{SiO}_{2}-\mathrm{CaO}$ and showed that even with a silica content up to $90 \% \mathrm{~mol}$, the bioactivity is retained. ${ }^{\mathbf{1 1}}$

As previously mentioned, bioactive glasses can also serve as multifunctional systems to be used not only for their bioactivity but also as a carrier for drugs, growth factors or other biomolecules. In this context, template glasses and mesoporous pure silica materials are the most commonly investigated due to their enhanced textural properties. In this sense, bioactive glass nanoparticles are of high importance. Their high surface to volume ratio make them an excellent candidate for bone regeneration. Additionally, these nanoparticles can serve as fillers in a polymeric matrix. ${ }^{12,13}$ Their morphological characteristics can improve their incorporation more homogeneously. Bioactive glass nanoparticles can also be used as coatings for metallic implants or for the preparation of injectable bioactive cements. $^{\mathbf{1 4}}$

Incorporation of metallic ions into the glass composition and the study of their effects on the glass properties have been the focus of many research papers in the past few years. ${ }^{15-17}$ This doping can give additional functionalities to the glass such as angiogenesis and antibacterial effects. ${ }^{16,17}$ One of the most investigated elements is magnesium. It is a trace alkali-earth metal naturally present in the human body. 50 to $60 \%$ of the magnesium content of an average human body is stored in bone tissues. ${ }^{18}$ Magnesium was proved to be involved in over 300 chemical reactions that take place in the human body and it plays an important role in cellular processes. ${ }^{19}$ For example, it can stimulate osteoblast proliferation, a process that is crucial for bone development, maintenance and repair. ${ }^{20}$ Additionally, $\mathrm{Mg}$ depletion results in impaired bone growth, increased loss in trabecular bone and bone resorption, highlighting the substantial role that $\mathrm{Mg}$ plays in bone metabolism. ${ }^{21}$ Doping bioactive glasses with magnesium has been previously investigated. $^{22}$ For instance, Dietrich et al. studied the effect of magnesium doping of $46 \mathrm{~S} 6$ on the in vitro bioactivity of this composition. They found that magnesium influences the formation and the evolution of the newly formed layers, and the intensity of these changes depends largely on magnesium content added in the glass matrix. ${ }^{23}$ Another study was performed by Riti et al. on the effect of synthesis route and magnesium addition on the structure and bioactivity of a solgel derived binary glass. The results demonstrated that $\mathrm{MgO}$ improves the bioactivity of glasses prepared by the alkali mediated route and inhibits it in those prepared by the acid route. ${ }^{24}$ Magnesium can enter the glass network as a modifier or an intermediate depending on its content and the overall glass composition..$^{22}$ In this context, there is still some controversy on its role in the glass network and its effect on the glass properties, including bioactivity. ${ }^{22}$ In the present study, we shed new light on the effect of magnesium doping on the properties of bioactive glasses. Herein, we investigate the acellular in vitro bioactivity as well as loading and release of amoxicillin of glasses in the system $85 \mathrm{SiO}_{2}-(15-x) \mathrm{CaO}-x \mathrm{MgO}$. The studied glasses have been produced using sol-gel chemistry with the incorporation of a structure directing agent. To the best of our knowledge, magnesium has never been studied under these circumstances. Accordingly, this paper gives additional insight on the effect of magnesium on glass bioactivity and its capacity to load and release an antibiotic agent.

\section{Materials and methods}

\section{Materials}

Tetraethyl orthosilicate $\left(\mathrm{SiC}_{8} \mathrm{H}_{20} \mathrm{O}_{4}\right)$, calcium nitrate tetrahydrate $\left(\mathrm{Ca}\left(\mathrm{NO}_{3}\right)_{2} \cdot 4 \mathrm{H}_{2} \mathrm{O}\right)$, magnesium nitrate hexahydrate $\left(\mathrm{Mg}\left(\mathrm{NO}_{3}\right)_{2} \cdot 6 \mathrm{H}_{2} \mathrm{O}\right)$, hexadecyltrimethylammonium bromide $\left(\mathrm{C}_{19} \mathrm{H}_{42} \mathrm{BrN}\right.$, CTAB), ethanol $\left(\mathrm{C}_{2} \mathrm{H}_{6} \mathrm{O}\right)$ and ammonia hydroxide $\left(\mathrm{NH}_{4} \mathrm{OH}\right)$ were used to produce the bioactive glass powders. For SBF and PBS (Phosphate Buffered Saline) preparation, the following chemicals were used: calcium chloride $\left(\mathrm{CaCl}_{2}\right)$, potassium chloride $(\mathrm{KCl})$, sodium chloride $(\mathrm{NaCl})$, sodium sulfate $\left(\mathrm{Na}_{2} \mathrm{O}_{4} \mathrm{~S}\right)$, sodium bicarbonate $\left(\mathrm{NaHCO}_{3}\right)$, sodium phosphate dibasic $\left(\mathrm{Na}_{2} \mathrm{HPO}_{4}\right)$ magnesium chloride hexahydrate $\left(\mathrm{MgCl}_{2} \cdot 6 \mathrm{H}_{2} \mathrm{O}\right)$, potassium phosphate dibasic trihydrate $\left(\mathrm{HK}_{2}\right.$ $\left.\mathrm{O}_{4} \mathrm{P} \cdot 3 \mathrm{H}_{2} \mathrm{O}\right)$, Trizma $\left(\mathrm{C}_{4} \mathrm{H}_{11} \mathrm{NO}_{3}\right)$ and hydrochloric acid ( $\left.\mathrm{HCl}\right)$. Toluene $\left(\mathrm{C}_{7} \mathrm{H}_{8}\right)$ and APTES $\left(\mathrm{H}_{2} \mathrm{~N}\left(\mathrm{CH}_{2}\right)_{3} \mathrm{Si}\left(\mathrm{OC}_{2} \mathrm{H}_{5}\right)_{3}\right)$ were employed for surface functionalization. All chemical products mentioned above were purchased from Sigma Aldrich and were used without further purification.

\section{Preparation of BG- $\mathrm{Mg}_{x}$ powders}

Five compositions of mesoporous bioactive glasses, as shown in Table 1, were prepared by the sol-gel method at room temperature, using hexadecyltrimethylammonium bromide (CTAB) as a structure directing agent. The synthesis was performed according to procedures described elsewhere, with slight modifications. ${ }^{25,26}$ Briefly, $1 \mathrm{~g}$ of the surfactant was dissolved in a mixture of distilled water $(150 \mathrm{ml})$, ethanol $(30 \mathrm{ml})$ and ammonium hydroxide $(2 \mathrm{ml})$, which was used as a catalyst. After dissolving CTAB, proper amounts of calcium nitrate tetrahydrate and magnesium nitrate hexahydrate were added to the mixture depending on the glass composition, followed by continuous stirring for 30 minutes. Then, $15.6 \mathrm{ml}$ of TEOS was added dropwise and the resultant solutions were stirred for four additional hours. The white precipitates were then filtered and washed with distilled water. After that, samples were dried at $80^{\circ} \mathrm{C}$ for 18 hours. Finally, they were thermally heat treated at $550{ }^{\circ} \mathrm{C}$ for 6 hours using a heating rate of $1^{\circ} \mathrm{C} \mathrm{min}{ }^{-1}$, in order to remove the remaining $\mathrm{CTAB}$ and nitrates.

Three of our glass powders, i.e. $\mathrm{BG}, \mathrm{BG}-\mathrm{Mg}_{3}$ and $\mathrm{BG}-\mathrm{Mg}_{5}$, were surface-functionalized with 3-aminopropyl groups by using a post-grafting procedure. Briefly, one gram of bioactive glass powder was dispersed in $100 \mathrm{ml}$ of toluene by ultrasonication for 30 minutes. After that, $5 \mathrm{ml}$ of APTES was added and the system was refluxed at $80{ }^{\circ} \mathrm{C}$ for 24 hours under a nitrogen atmosphere. The powder was then collected by filtration, washed with toluene and ethanol and dried at $100{ }^{\circ} \mathrm{C}$ for 18 hours. The amino functionalized glasses were designated as n-BG, n-BGMg 3 and n-BGMg . 
Table 1 Molar compositions of the studied glasses

\begin{tabular}{|c|c|c|c|c|}
\hline BG & 85 & 15 & 0 & $85 \mathrm{SiO}_{2}-15 \mathrm{CaO}$ \\
\hline $\mathrm{BG}-\mathrm{Mg}_{1}$ & 85 & 14 & 1 & $85 \mathrm{SiO}_{2}-14 \mathrm{CaO}-1 \mathrm{MgO}$ \\
\hline $\mathrm{BG}^{-\mathrm{Mg}_{5}}$ & 85 & 10 & 5 & $85 \mathrm{SiO}_{2}-10 \mathrm{CaO}-5 \mathrm{MgO}$ \\
\hline BG-Mg ${ }_{10}$ & 85 & 5 & 10 & $85 \mathrm{SiO}_{2}-5 \mathrm{CaO}-10 \mathrm{MgO}$ \\
\hline
\end{tabular}

\section{Characterization}

The chemical composition of our powders was determined using Inductively Coupled Plasma-Atomic Emission Spectroscopy (ICP-AES), which was performed on a JobinYvon HoribaUltima 2 apparatus. The results were obtained using the average of three measurements.

Structural characterization was performed using X-ray Diffraction (XRD) and Fourier Transformed Infrared Spectroscopy in Attenuated Total Reflection mode (FTIR-ATR). The XRD patterns of all calcined powders were recorded using an automated X-ray powder diffractometer (PAnalytical) using $\mathrm{CuK} \alpha$ radiation at a voltage and current of $45 \mathrm{kV}$ and $40 \mathrm{~mA}$, respectively. The data were collected in the $2 \theta$ range of $10-60^{\circ}$. FTIRATR analysis was conducted on bioactive glass powders using an IS50 spectrometer. The samples were analyzed in a total of 64 iterations in the range of 400 to $4000 \mathrm{~cm}^{-1}$ with a resolution of $4 \mathrm{~cm}^{-1}$. Thermogravimetric Analysis (TGA) was carried out on the dried samples using a TA Instruments Q500 thermal analyzer to determine the appropriate stabilization temperature. The scans were performed using a heating rate of $10{ }^{\circ} \mathrm{C} \min ^{-1}$ to a maximum temperature of $1000{ }^{\circ} \mathrm{C}$ under an air atmosphere.

Textural properties were determined from $\mathrm{N}_{2}$-gas adsorption/ desorption analysis using a 3Flex from Micromeritics. Measurements were performed at $77.37 \mathrm{~K}$. Before each measurement, samples were degassed at $100{ }^{\circ} \mathrm{C}$ for 12 hours to remove moisture and any other contaminants from the surface. Surface area was obtained by means of the Brunauer-Emmett-Teller (BET) method, ${ }^{27}$ whereas total pore volume was calculated from the amount of $\mathrm{N}_{2}$ adsorbed at a relative pressure of 0.95 , corresponding to complete pore filling, and the pore size distribution was obtained using the Barrett-Joyner-Halenda (BJH) method. ${ }^{28}$

The morphology of the samples was examined using Scanning Electron Microscopy (SEM) under high vacuum, at an accelerated voltage between 12.5 and $15 \mathrm{kV}$ after being coated with carbon.

\section{Bioactivity assessment}

The in vitro bioactivity of the prepared glass samples was assessed by immersion in Simulated Body Fluid (SBF), prepared as described by Kokubo et al. ${ }^{29} \mathrm{All}$ specimens were immersed for
3,6 , or 12 hours or $1,3,7$, or 14 days. SBF is an ionic solution in which the concentration of each ion is similar to that of human plasma, as shown in Table 2. The test was performed using BG powders. Equal amounts of samples were incubated in SBF at a concentration of $2 \mathrm{mg} / 1 \mathrm{ml}$ in clean and sterile bottles at $37^{\circ} \mathrm{C}$ under continuous stirring. After each selected period, samples were removed from the SBF by filtration, washed with distilled water and dried at $60{ }^{\circ} \mathrm{C}$ for 24 hours. The phase and chemical structure of the obtained samples were then characterized using FTIR spectroscopy and XRD. For detecting the crystallite formation, the surface samples were examined by using Scanning Electron Microscopy (SEM). Furthermore, the $\mathrm{pH}$ value of all the filtrated solutions was measured as well.

\section{Drug loading and release}

Loading. Amoxicillin (Scheme 1) was chosen as the model drug molecule for the loading and release study of antibiotics. The study was performed by monitoring the changes of UV absorbance at the wavelength of $272 \mathrm{~nm}$. The amoxicillin concentration was obtained through a standard curve that obeys the Beer-Lambert law. A series of aqueous solutions of amoxicillin with known concentrations $\left(0.03-0.50 \mathrm{mg} \mathrm{ml}^{-1}\right)$ was prepared and the absorbance was measured by using a PerkinElmer lambda 850 UV spectrometer.

For drug loading, $0.2 \mathrm{~g}$ of amino-functionalized glasses was dispersed in a $4 \mathrm{mg} \mathrm{ml}^{-1}$ aqueous solution of amoxicillin. The resulting solution was kept under continuous stirring for 24 hours. Then, bioactive glass loaded powders were collected by centrifugation at $10000 \mathrm{rpm}$. The supernatants were analyzed using a UV spectrometer and the powders were dried at $60^{\circ} \mathrm{C}$ for 24 hours. The loading efficiency of the three compositions was determined by using the following equation:

$$
\text { loading efficiency }=\frac{C_{\mathrm{i}}-C_{\mathrm{f}}}{C_{\mathrm{i}}} \times 100 \%
$$

where $C_{\mathrm{i}}$ is the initial concentration of amoxicillin; $C_{\mathrm{f}}$ is the final concentration of the drug, which was calculated using the standard curve equation.

Drug release. An in vitro release study of amoxicillin was performed using phosphate buffered saline $(\mathrm{pH}=7.4)$ as

Table 2 Ion concentration ( $\mathrm{mM}$ ) in SBF and human blood plasma

\begin{tabular}{lcccccccc}
\hline Ion & $\mathrm{Na}^{+}$ & $\mathrm{K}^{+}$ & $\mathrm{Ca}^{+}$ & $\mathrm{Mg}^{+}$ & $\mathrm{Cl}^{-}$ & $\mathrm{HCO}_{3}^{-}$ & $\mathrm{HPO}_{4}{ }^{2}$ & $\mathrm{SO}_{4}{ }^{2-}$ \\
\hline SBF & 142 & 5 & 2.5 & 1 & 147.8 & 4.2 & 1 \\
Human blood plasma & 142 & 5 & 2.5 & 1.5 & 103 & 27 & 0.5 \\
\end{tabular}


<smiles>CN1[C@@H](C(=O)O)[C@H](NC(=O)[C@@H](N)c2ccc(O)cc2)SC1(C)C</smiles>

Scheme 1 Chemical structure of an amoxicillin drug molecule.

a release medium. Briefly, $0.1 \mathrm{~g}$ of the loaded bioactive glass powders was dispersed in $50 \mathrm{ml}$ of PBS and kept under continuous stirring at $37^{\circ} \mathrm{C}$. After each selected time point, $4 \mathrm{ml}$ was withdrawn and filtered, and another $4 \mathrm{ml}$ of fresh PBS was added to the solution, keeping the total volume at $50 \mathrm{ml}$. The filtrated solution was analyzed by using UV-vis spectrometry and the concentration was calculated by using the standard equation. The cumulative release profile of amoxicillin in PBS was determined through the following equation: ${ }^{30}$

$$
C_{i, \text { cumul }}=\frac{V_{\mathrm{a}}}{V_{\mathrm{t}}} \times \sum C_{i-1}+C_{i}
$$

where $C_{i, \text { cumul }}$ is the cumulative concentration; $C_{i}$ is the concentration at time $i$; $C_{i-1}$ is the concentration at time $i-1$; $V_{\mathrm{a}}$ is the volume of the withdrawn solution and $V_{\mathrm{t}}$ is the volume of the total solution.

\section{Results and discussion}

\section{Thermogravimetric analysis}

Fig. 1 shows the TGA results of the as-dried powders. It was found that the total weight loss of the samples increases with $\mathrm{MgO}$ content after the heat treatment of the powders from room temperature to $1000{ }^{\circ} \mathrm{C}$. The same observations were also noted by Mariappan C. R. et al. when they studied the influence of silver on the structure of bioglass-ceramic nanoparticles. ${ }^{31}$ The first range between $30{ }^{\circ} \mathrm{C}$ and $220{ }^{\circ} \mathrm{C}$ corresponds to the loss of physically adsorbed water molecules (from 30-120 ${ }^{\circ} \mathrm{C}$ ) and condensation of silanol groups present at the surface of the nanoparticle samples (from $120-220{ }^{\circ} \mathrm{C}$ ). For $\mathrm{BG}-\mathrm{Mg}_{10}$, there was only a $4 \mathrm{wt} \%$ weight loss around $120{ }^{\circ} \mathrm{C}$ while $\mathrm{BG}-\mathrm{Mg}_{3}$ recorded a significant weight loss of approximately $7 \mathrm{wt} \%$ in the same temperature range, mainly due to its ability to absorb more water molecules. In the range of $220-550{ }^{\circ} \mathrm{C}$, a significant weight loss was noted for all samples, of about $14 \mathrm{wt} \%$, which can be associated with the elimination of residual CTAB template, and residual nitrate and alkoxide groups that did not react during synthesis. Above $550{ }^{\circ} \mathrm{C}$, the weight loss reached a steady state for all samples (73-75 wt\%). In summary, all materials were heat treated at $550{ }^{\circ} \mathrm{C}$ before being used for the rest of this work.

\section{Composition}

The results obtained through ICP-AES analysis are presented in Table 3 as an average of three measurements. The experimental composition of the sample was revealed to be close to the nominal composition. Silica content was found to be lower than the nominal value for all compositions. This might indicate that

Table 3 Molar compositions determined via ICP-AES

\begin{tabular}{llrl}
\hline & \multicolumn{3}{c}{ Molar composition determined by ICP-AES } \\
\cline { 2 - 4 } Sample acronym & $\mathrm{SiO}_{2} \% \mathrm{~mol}$ & $\mathrm{CaO} \% \mathrm{~mol}$ & $\mathrm{MgO} \% \mathrm{~mol}$ \\
\hline $\mathrm{BG}$ & $77.08 \pm 0.04$ & $15.09 \pm 0.06$ & 0.0000 \\
$\mathrm{BG}-\mathrm{Mg}_{1}$ & $77.96 \pm 0.02$ & $14.77 \pm 0.06$ & $1.06 \pm 0.05$ \\
$\mathrm{BG}-\mathrm{Mg}_{3}$ & $77.48 \pm 0.07$ & $11.47 \pm 0.04$ & $2.50 \pm 0.04$ \\
$\mathrm{BG}-\mathrm{Mg}_{5}$ & $78.52 \pm 0.05$ & $9.95 \pm 0.02$ & $5.18 \pm 0.03$ \\
$\mathrm{BG}-\mathrm{Mg}_{10}$ & $78.24 \pm 0.03$ & $4.87 \pm 0.04$ & $10.64 \pm 0.05$
\end{tabular}

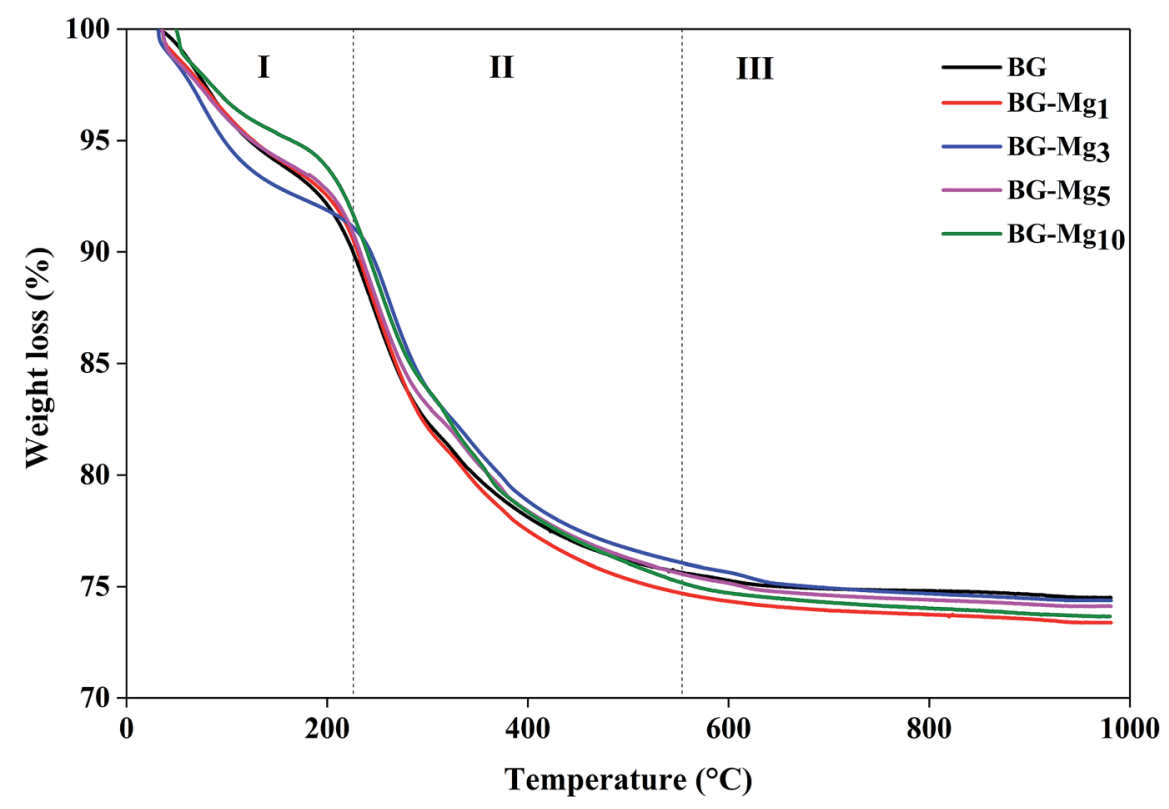

Fig. 1 TGA profiles of bioactive glass powders. 
the amount of TEOS added during synthesis did not react totally and that the unreacted precursor molecules were most likely washed out during filtration. Overall, these results suggest the successful sol-gel synthesis of the present bioactive glass series.

\section{Structural properties}

Fig. 2 displays the XRD patterns for the glasses $85 \mathrm{SiO}_{2}-(15-x)$ $\mathrm{CaO}-x \mathrm{MgO}(0 \leq x \leq 10)$ synthesized by the sol-gel route. All samples exhibited a broad peak between $15^{\circ}$ and $30^{\circ}$ after heat treatment at $550{ }^{\circ} \mathrm{C}$. This indicates the absence of any crystalline phase and the presence of an entirely amorphous structure characteristic of the glassy phase, despite the increasing amount of magnesium. It is also important to point out that all five patterns are the same and did not contain diffraction peaks, revealing a disordered arrangement at the nanoscale level. This suggested that magnesium ions were successfully introduced into the glass structure. The same results were also obtained by El-Fiqi et $a l .^{32}$ and Riti et al. ${ }^{24}$

The infrared absorption spectra of the five silicate materials after calcination at $550{ }^{\circ} \mathrm{C}$ are shown in Fig. 3. The results indicate the presence of three characteristic main bands allocated to different vibration modes of the Si-O-Si bonds. ${ }^{33-35}$ The first peak at $430 \mathrm{~cm}^{-1}$ corresponds to the rocking vibration of the $\mathrm{Si}-\mathrm{O}-\mathrm{Si}$ bending mode. The second band at $800 \mathrm{~cm}^{-1}$ was assigned to the symmetric stretching vibration of $\mathrm{Si}-\mathrm{O}$. It is worth noting that there is a shoulder at approximately $960 \mathrm{~cm}^{-1}$ before calcination (results not shown), which is related to the stretching vibration of $\mathrm{Si}-\mathrm{OH}$ bonds, but it disappears totally after calcination, indicating the increase in network connectivity and the formation of more bridging oxygen. ${ }^{35}$ The third peak located at around $1030 \mathrm{~cm}^{-1}$ corresponds to the $\mathrm{Si}-\mathrm{O}-\mathrm{Si}$ asymmetric stretching mode, and it is the most pronounced in the spectrum of $\mathrm{Mg}$ free bioglass $85 \mathrm{~S} 15 \mathrm{C}$. This band represents the silica network of $\mathrm{BG}^{-\mathrm{Mg}_{x}}$. The same bands were also observed in the work of Arcos et $a .^{36}$ for mesoporous $85 \mathrm{SiO}_{2}-$ $10 \mathrm{CaO}-5 \mathrm{P}_{2} \mathrm{O}_{5}$ bioactive glass.

It is important to point out that a calcination temperature above $450{ }^{\circ} \mathrm{C}$ is necessary in order to successfully incorporate the $\mathrm{Ca}^{2+}$ and $\mathrm{Mg}^{2+}$ ions into the glass structure. ${ }^{37-39}$ FTIR spectra and XRD patterns of the different bioactive glass compositions did not show major differences. In this work, the total modifier molar percentage is equal to $15 \%$ in all compositions. For this reason, we believe that only minor changes could be detected through FTIR and XRD analysis. Galiano et al. ${ }^{\mathbf{4 0}}$ studied $\mathrm{Mg}$ and Sr incorporation in the glass network. In this study, the authors found that alkaline earth metals do not have an influence on the distribution of the Qn species in the silica network as long as the total RO fraction did not change, where $\mathrm{R}=\mathrm{Ca}, \mathrm{Mg}, \mathrm{Sr}$. This also confirms why the FTIR spectra of different glasses recorded in this work did not show much of a difference. The same conclusions were obtained by Pedone et al., ${ }^{\mathbf{4 1}}$ where the short range distribution of the Qn species did not change when varying $\mathrm{MgO}$ content in the glass composition. These results support our assumptions on the structural analysis of our glass powders with different $\mathrm{CaO} / \mathrm{MgO}$ ratios.

\section{Textural properties}

$\mathrm{N}_{2}$ adsorption isotherm analyses were performed to determine the textural properties of the bioactive glasses in terms of surface area, pore volume and pore size distribution. Fig. 4 shows the adsorption/desorption isotherms obtained for various compositions. According to the recent update of the IUPAC classification, ${ }^{42}$ all samples revealed a type (IVa) isotherm with a hysteresis loop between 0.4 and $0.9 P / P_{0}$. The characteristic hysteresis loop is observed in all cases, which evidenced the presence of mesopores in the glasses. However, there are noticeable differences in the shape of the hysteresis. As can be seen, the closing point of the hysteresis, the $P / P_{0}$

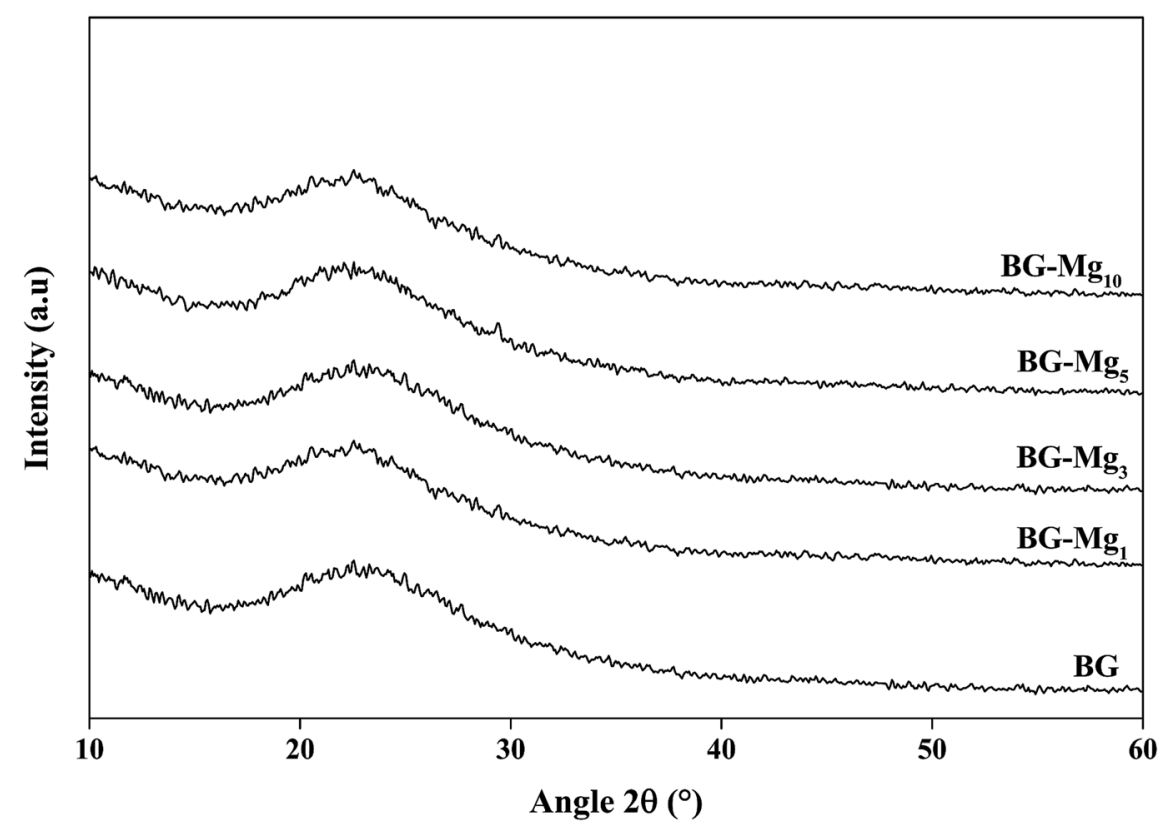

Fig. 2 XRD patterns of the glasses after heat treatment at $550^{\circ} \mathrm{C}$. 


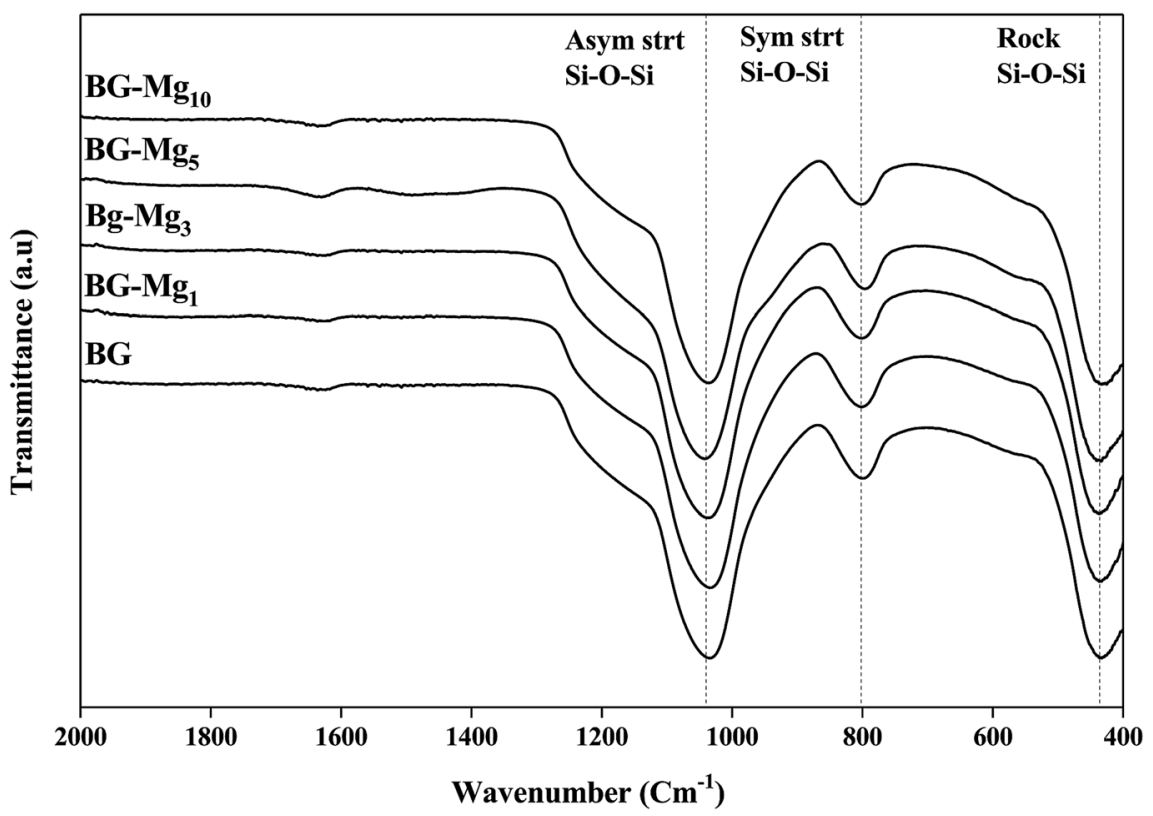

Fig. 3 FTIR spectra of bioactive glass powders calcined at $550{ }^{\circ} \mathrm{C}$.

pressure at which the desorption branch joins the adsorption branch, shifts to higher values as the magnesium content in the glasses increased. For BG, BG- $\mathrm{Mg}_{5}$ and $\mathrm{BG}-\mathrm{Mg}_{10}$, an isotherm with type $\mathrm{H} 5$ hysteresis was observed. This suggests that these three compositions contain both open and partially blocked mesopores. Concerning $\mathrm{BG}-\mathrm{Mg}_{1}$ and $\mathrm{BG}-\mathrm{Mg}_{3}$, a hysteresis of type $\mathrm{H} 2$ (a) was observed, which indicates the existence of inkbottle shaped pores. Examples of this type of hysteresis loop have been observed with mesocellular silica foams and certain mesoporous ordered silica after hydrothermal treatment. ${ }^{42}$

Surface area was determined by means of the BET method. According to the calculations, surface area increases with increasing magnesium content in the glass composition, as indicated in Table 4. As can be evidenced, the surface area increased from 211 to $311 \mathrm{~m}^{2} \mathrm{~g}^{-1}$, and the pore volume increased from 0.2616 to $0.4127 \mathrm{~cm}^{3} \mathrm{~g}^{-1}$, when going from BG to $\mathrm{BG}-\mathrm{Mg}_{10}$. Our results are similar to those found by Li et al. ${ }^{\mathbf{4 3}}$ in which surface area increased with increasing $\mathrm{Mg}$ molar substitution of $\mathrm{Ca}$ in the system $\mathrm{Si}-\mathrm{Ca}-\mathrm{P}-\mathrm{Mg}$.

\section{Bioactivity assessment}

The essential sign of bioactivity is the ability to form an apatite layer on the glass surface that chemically bridges the bone and the implant. To determine the bioactivity of the synthesized glasses, they were subjected to in vitro solution testing using

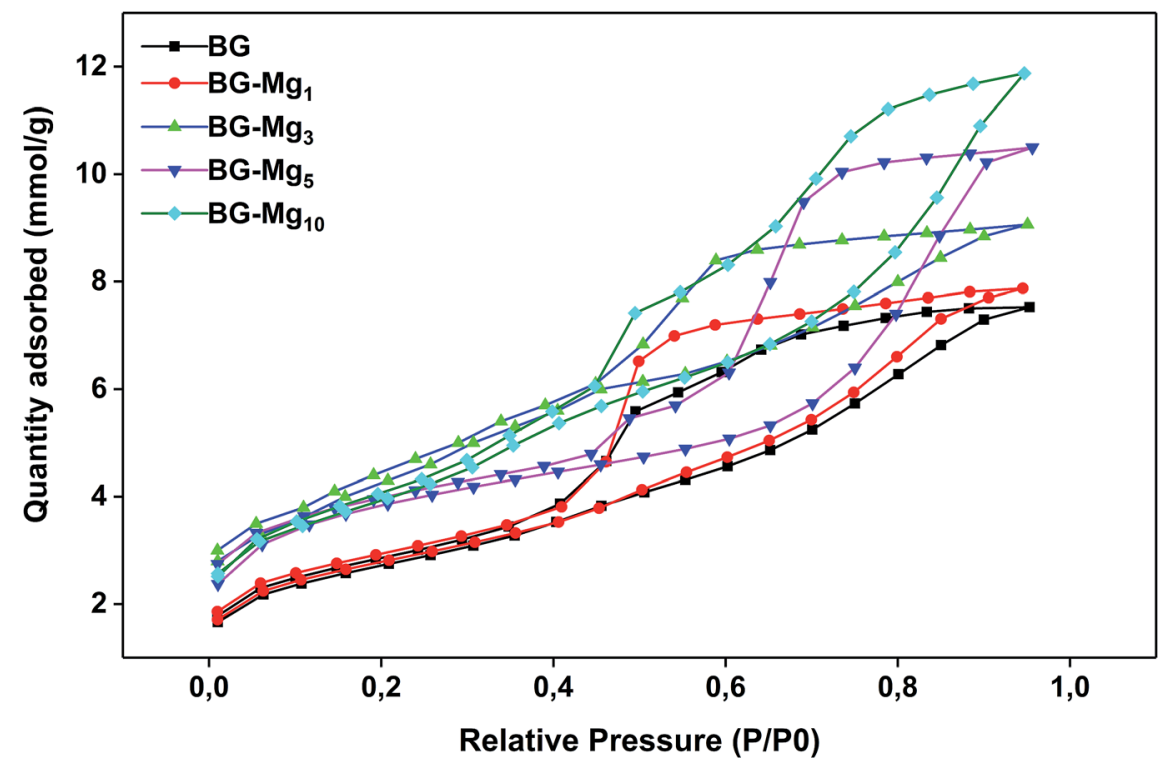

Fig. $4 \quad N_{2}$ adsorption-desorption isotherms for all studied glasses. 
Table 4 Textural properties of the examined glasses

\begin{tabular}{|c|c|c|c|c|}
\hline Composition & $\begin{array}{l}\text { Surface } \\
\text { area } \mathrm{m}^{2} \mathrm{~g}^{-1}\end{array}$ & $\begin{array}{l}\text { Total pore } \\
\text { volume } \mathrm{cm}^{3} \mathrm{~g}^{-1}\end{array}$ & $\begin{array}{l}\text { Average pore } \\
\text { size } \mathrm{nm}\end{array}$ & $\begin{array}{l}\text { Average } \\
\text { particle size } \mathrm{nm}\end{array}$ \\
\hline BG & 211.6407 & 0.2616 & 5.1598 & 28.3499 \\
\hline BG-Mg & 250.3050 & 0.3090 & 5.3887 & 25.1997 \\
\hline BG-Mg ${ }_{5}$ & 284.2020 & 0.3649 & 5.4366 & 21.1117 \\
\hline BG-Mg ${ }_{10}$ & 311.9174 & 0.4127 & 5.4933 & 19.2359 \\
\hline
\end{tabular}

SBF medium. The samples were soaked in SBF at $37{ }^{\circ} \mathrm{C}$ for different periods of time from 1 hour to 14 days. After each time period, the solutions were filtered, their $\mathrm{pH}$ was measured and the powders were analyzed using FTIR spectroscopy, XRD and SEM.

Fig. 5 shows the FTIR spectra of the samples after soaking in SBF for different periods of time. The comparison between the spectra before and after immersion in SBF displays the appearance of additional peaks around $500 \mathrm{~cm}^{-1}$ after only 3 hours of testing for all studied glasses, ${ }^{34}$ related to the antisymmetric vibration mode of $\mathrm{P}-\mathrm{O}$ in an amorphous $\mathrm{Ca}-\mathrm{P}$ layer, which indicate the formation of apatite in SBF. In addition, after 3 days of soaking for $\mathrm{BG}, \mathrm{BG}-\mathrm{Mg}_{1}$ and $\mathrm{BG}-\mathrm{Mg}_{3}$ (data not shown), the spectra exhibit absorption bands at 560 and $604 \mathrm{~cm}^{-1}$, corresponding to the $\mathrm{P}-\mathrm{O}$ vibrational mode in a crystalline phosphate phase. ${ }^{\mathbf{1 4 , 3 1}}$ However, BG-Mg ${ }_{5}$ and BG$\mathrm{Mg}_{10}$ powders did not exhibit any crystallization of the amorphous Ca-P already deposited after only 3 hours of immersion. These results led us to suggest that $\mathrm{Mg}$ incorporation in the glass composition has a retarding effect on the crystallization of the Ca-P amorphous layer deposited in the early stages of the bioactivity test. To further confirm our assumption, XRD analysis was conducted after 14 days in SBF. The XRD patterns of samples after 14 days in SBF are displayed in Fig. 6. These patterns show the broad band characteristic of internal disorder and the glassy nature of these materials. However, new wide reflection peaks can be detected for some samples, indicating the formation of a poorly crystallized hydroxyapatite phase. For BG and $\mathrm{BG}^{-\mathrm{Mg}_{x}}(x=1,3,5)$, the XRD patterns indicate the presence of two additional peaks at $25^{\circ}$ and $32^{\circ}$, which can be ascribed to diffraction of the (002) and (211) planes in a poorly crystalline apatite phase, ${ }^{\mathbf{4 4}}$ respectively. For BG- $\mathrm{Mg}_{3}$ and BG$\mathrm{Mg}_{5}$, the peak situated at $32^{\circ}$ becomes wider while the intensity of the peak situated at $25^{\circ}$ showed a reduction in its intensity. In the case of BG- $\mathrm{Mg}_{10}$, no sign of a crystalline phase could be observed. These findings are in good accordance with the FTIR observations.

Fig. 7-9 show the SEM images and EDS spectra of BG, BG$\mathrm{Mg}_{3}$ and $\mathrm{BG}-\mathrm{Mg}_{5}$ before and after 14 days of immersion in SBF. Before soaking, the micrographs show particles with spherical and regular shapes. A slight decrease in particle size was also noticed when the amount of magnesium was increased, see Fig. 7, 8 and 9(a). EDS analysis of the bioactive glass powder confirmed the presence of $\mathrm{Mg}$ and $\mathrm{Ca}$ elements in the glass nanoparticles. Comparing the EDS results with the theoretical values of the elemental composition of our bioactive glass nanoparticles, it was found that a gap exists between the sets of data. However, the EDS values were obtained only for the surface. It is hypothesized that the distribution of cations in the glass nanoparticles is not uniform. This difference in composition may also originate from the washing step during synthesis, which leads to the loss of unreacted chemicals along with poorly adhered cations on the surface, since the modifier cations such as calcium are present on the surface of the glass particles and do not enter the glass structure until heat treatment.

After 14 days in SBF (Fig. 7, 8 and 9(b)), it was observed that for the BG composition, the nanoparticle formation appeared to be impeded with the newly formed layer of small Ca-P crystallites, which confirms their bioactivity, as was also reported by other research groups. ${ }^{\mathbf{1 1 , 4 5 , 4 6}}$ In the case of BG- $\mathrm{Mg}_{3}$ and $\mathrm{BG}-\mathrm{Mg}_{5}$, the SEM images did not present the globular shape frequently found for apatite, but only showed that the particles had agglomerated, indicating the formation of an accentuated pseudo-crystalline calcium phosphate layer on their surfaces and between the particles. These results are consistent with the FTIR and XRD observations. All these findings indicated that magnesium has a retarding effect on the bioactivity of the glass and more precisely on the crystallization of the $\mathrm{Ca}-\mathrm{P}$ amorphous layer. Works done by other research groups showed the same retarding effect of $\mathrm{Mg}$ on glass bioactivity. ${ }^{22}$ It is supposed that $\mathrm{Mg}$ may enter the formed nuclei of hydroxyapatite, which results in changing its physico-chemical properties and thus hindering its growth. ${ }^{47}$ It was also reported that $\mathrm{Mg}$ favors the formation of amorphous calcium phosphate and suppresses its crystallization when it is present at high concentrations. ${ }^{48}$

The variation of $\mathrm{pH}$ in SBF medium as a function of time for $\mathrm{BG}, \mathrm{BG}-\mathrm{Mg}_{1}, \mathrm{BG}-\mathrm{Mg}_{3}, \mathrm{BG}-\mathrm{Mg}_{5}$ and $\mathrm{BG}-\mathrm{Mg}_{10}$ is presented in Fig. 10. As can be seen, the five samples exhibited almost the same $\mathrm{pH}$ variation profile with a perpendicular trend during the first hour followed by a slight decrease at $3 \mathrm{~h}$ then a stabilization of $\mathrm{pH}$ values until the end of the test. The same changes were detected by Balamurugan et al. ${ }^{\mathbf{9}}$

In a general way, for the first few hours of the test, a rapid dissolution of the glass surface occurs, which is accompanied by an ionic exchange between the $\mathrm{Ca}^{2+}$ and $\mathrm{Mg}^{2+}$ ions from the glass and $\mathrm{H}^{+}$ions present in the SBF. Moreover, the variation of $\mathrm{pH}$ depends closely on $\mathrm{Mg}$ content in the bioactive glass compositions..$^{50} \mathrm{pH}$ values at one hour of immersion in SBF for $\mathrm{BG}, \mathrm{BG}-\mathrm{Mg}_{5}$ and $\mathrm{BG}-\mathrm{Mg}_{10}$ are 7.92, 8.05 and 8.13, respectively. This suggest that glasses with a higher $\mathrm{Mg}$ content are more prone to dissolution. ${ }^{51}$ This is in contrast to other research, ${ }^{50,52}$ 

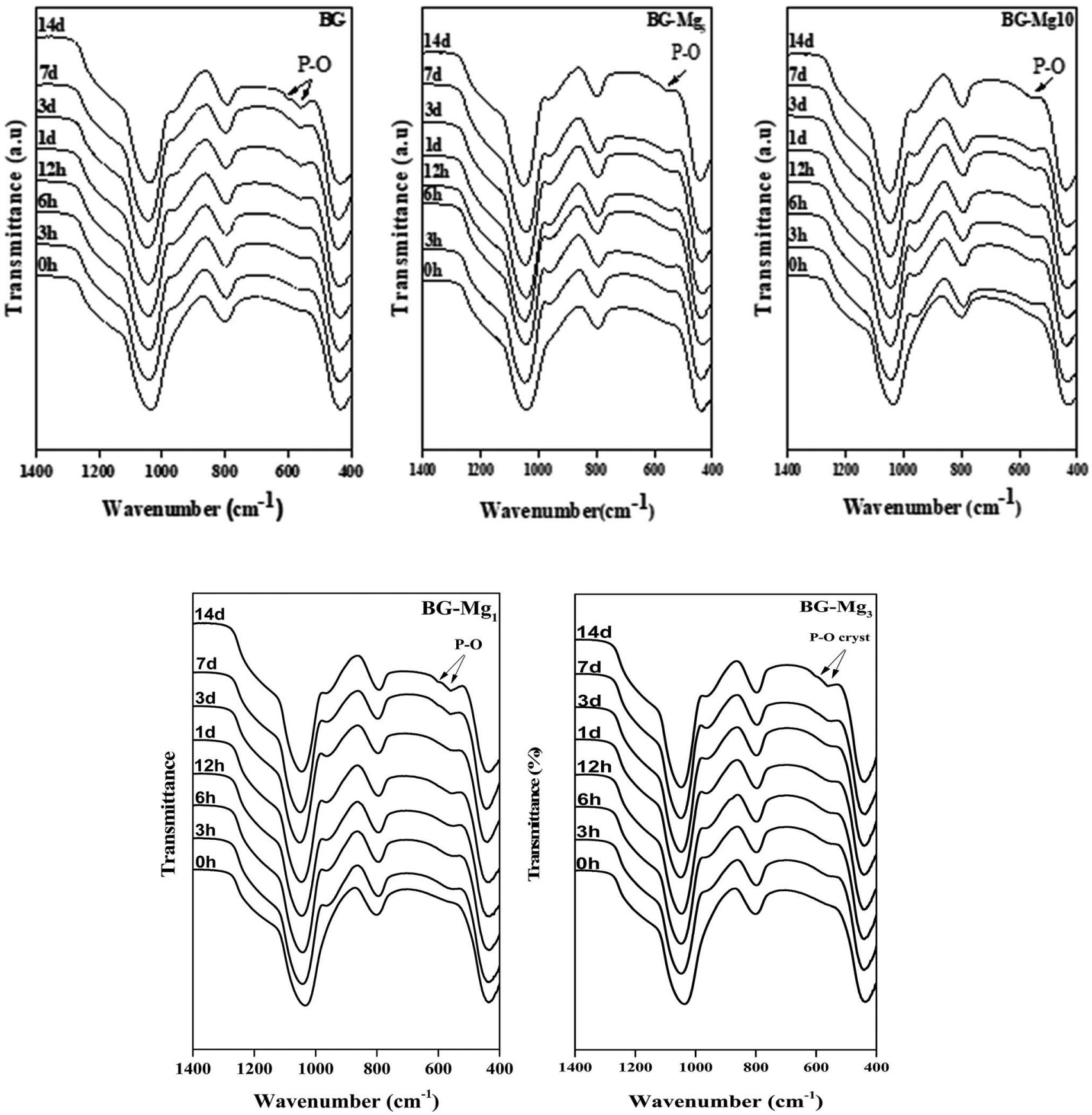

Fig. 5 FTIR spectra of BG0, BG-Mg after each period in the bioactivity test.

in which the authors found that $\mathrm{Mg}$ incorporation tends to slow down the glass dissolution when in contact with a biological medium. Our assumption can be explained by the fact that glasses doped with high magnesium fractions have higher surface areas than those with no, or lower $\mathrm{Mg}$ content. With higher surface areas, bioactive glasses are more prone to dissolution and to have a more intense ionic exchange between their surface and the surrounding medium. As a result, there is a significant increase of the $\mathrm{pH}$ of the SBF solutions.

L. Hench ${ }^{5}$ proposed that the mechanism of bioactivity involves five steps: glass dissolution and ionic exchange between the glass surface and the biological medium, repolymerization of a silica rich layer on the surface, formation of an amorphous $\mathrm{Ca}-\mathrm{P}$ layer and finally the crystallization of this layer into a carbonated hydroxyapatite (CHA). It is worth mentioning that hydroxyapatite is the most stable phase of calcium phosphates. ${ }^{53}$ Therefore, the ups and down observed in the $\mathrm{pH}$ variation profiles during the first few hours of the test could be related to the dissolution of a less stable Ca-P phase until its final stabilization. ${ }^{50}$ Additionally, $\mathrm{Mg}$ doped hydroxyapatite has been shown to have a faster dissolution rate. ${ }^{54}$ This was explained by the fact that $\mathrm{Mg}^{2+}$ has a smaller radius compared to $\mathrm{Ca}^{2+}$ (0.72 and 1.00 , respectively), which creates voids between particles. 


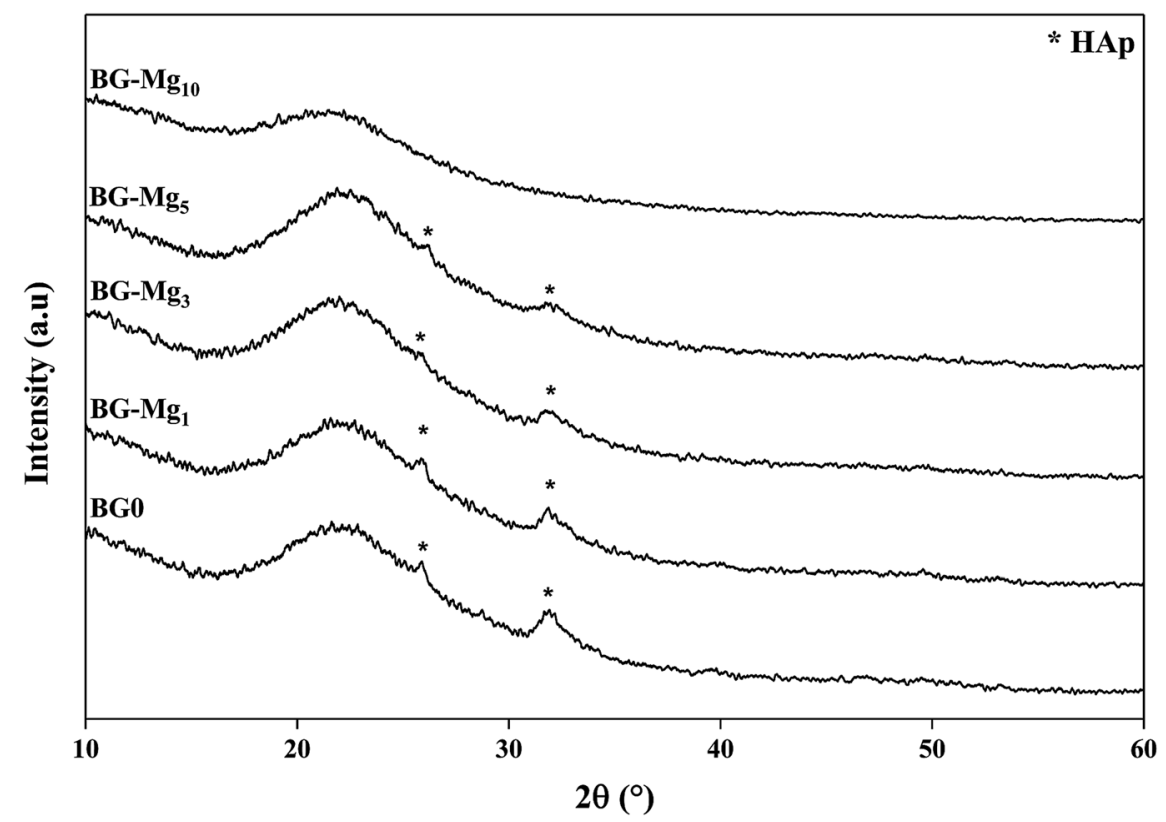

Fig. 6 XRD patterns of the BG-Mg series after 14 days of immersion in SBF.

\section{Kinetics of drug delivery}

Bioactive glass nanoparticles are rich with hydroxide $(\mathrm{OH})$ groups on their surface, which confer to them a net negative surface charge. This negatively charged surface is considered as a major hurdle in loading negatively charged biomolecules such as amoxicillin. ${ }^{55}$ To overcome this obstacle, the surface of the

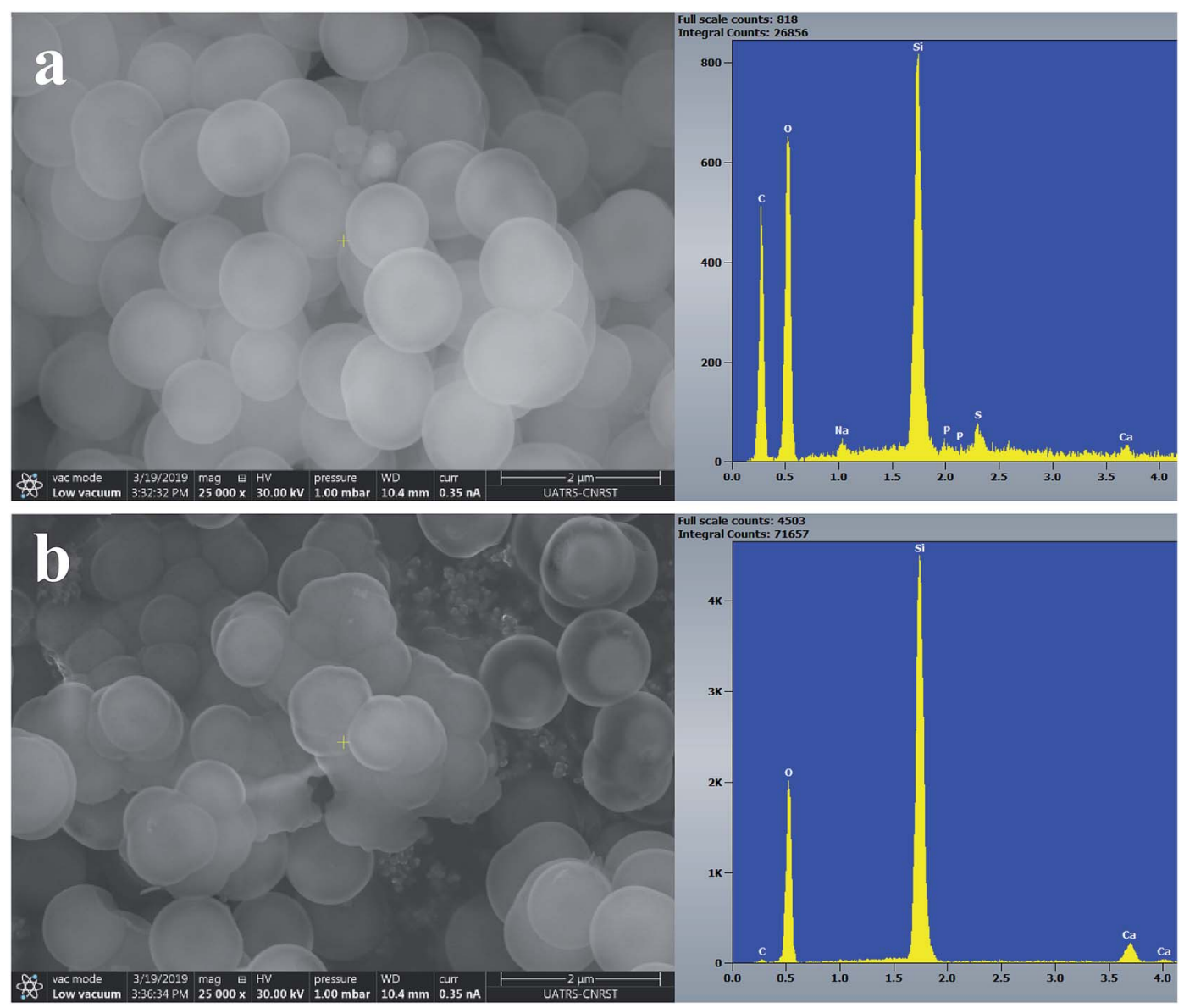

Fig. 7 SEM images of BGO (a) before and (b) after 14 days of immersion in SBF. 

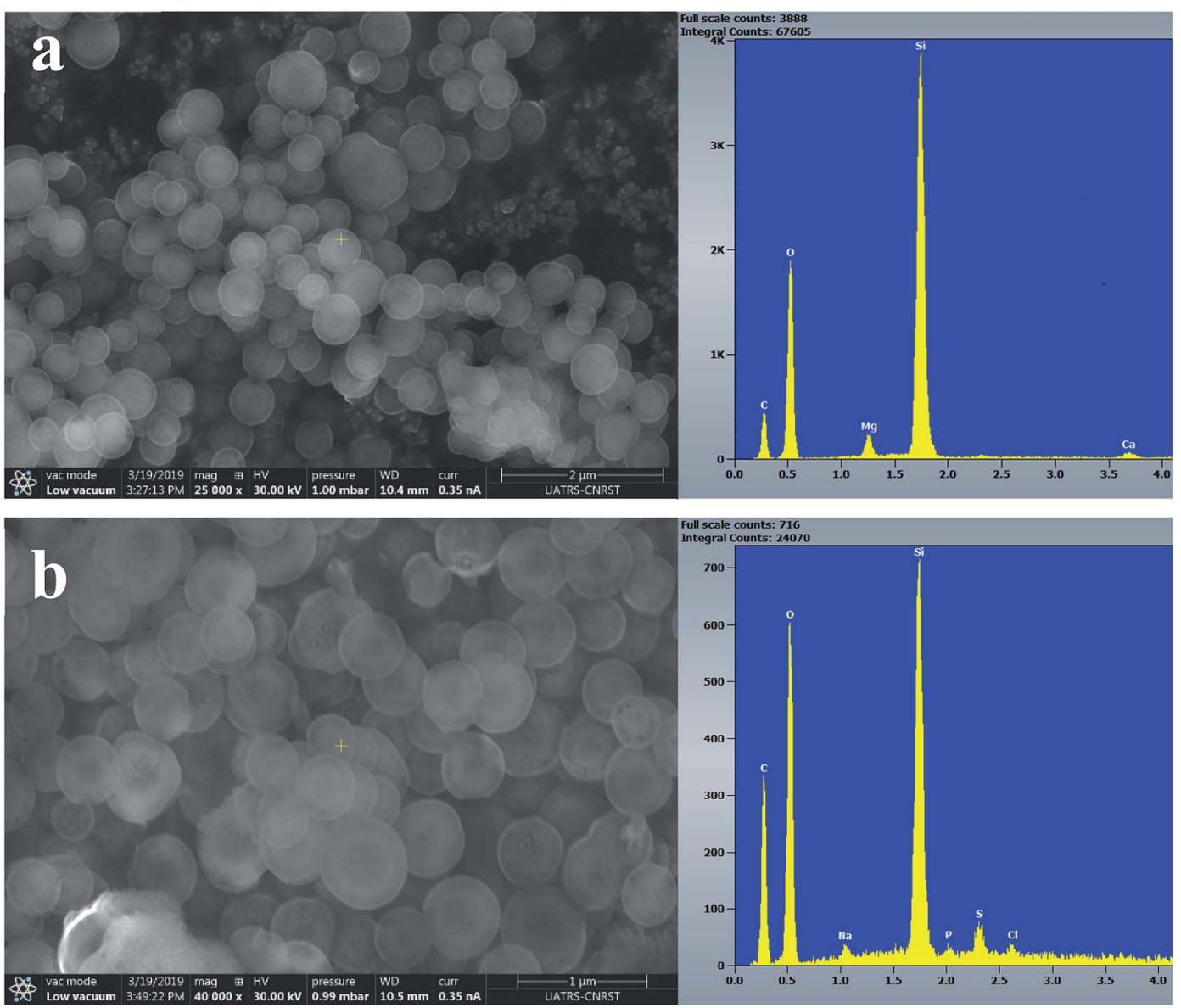

Fig. 8 SEM images of $\mathrm{BG}-\mathrm{Mg}_{3}(\mathrm{a})$ before and (b) after 14 days of immersion in SBF.

glass particles was modified. For this purpose, surface amination was used. It was hypothesized that after functionalization, the surface status would change from hydroxyl groups to amino groups, and thus the behavior of our nanoparticles would change when interacting with biomolecules of a negative charge nature. During biomineralization in SBF, it was shown that n$\mathrm{BG}, \mathrm{n}-\mathrm{BG}-\mathrm{Mg}_{3}$ and $\mathrm{n}-\mathrm{BG}-\mathrm{Mg}_{5}$ presented a pseudocrystalline structure after 14 days of immersion, and therefore they were chosen for drug release testing. The FTIR spectra of the samples aminated with APTES are shown in Fig. 11. The spectra reveal the presence of two additional peaks at 730 and $695 \mathrm{~cm}^{-1}$ compared to the non-aminated powders whose spectra present only the characteristic bands of $\mathrm{Si}-\mathrm{O}-\mathrm{Si}$ and $\mathrm{Si}-\mathrm{O}$ functional groups, as shown in Fig. 4. These new peaks are related to the vibration mode of the $\mathrm{N}-\mathrm{H}$ bond in the amino group. ${ }^{26}$ This result suggests the successful functionalization of the bioactive glasses. The presence of amino groups instead of hydroxyl groups on the bioactive glass surfaces is supposed to help in increasing the drug loading capacity of our glass powders since there will be more sites of interaction between the drug and the functionalized surface. ${ }^{56}$

In order to figure out the relationship between surface area and the amount of APTES grafted on the bioglasses, TGA tests were performed. As can be deduced from Fig. 12, the amount of
APTES increased with increasing surface area from n-BG to nBG- $\mathrm{Mg}_{5}$, as can be seen by the total weight loss around $850^{\circ} \mathrm{C}$. According to the data, it was also observed that there are three stages of weight loss. The first one corresponded to the removal of physically adsorbed water (until $200{ }^{\circ} \mathrm{C}$ ). More weight loss started from the end of the first weight loss stage $\left(200^{\circ} \mathrm{C}\right)$ until about $470^{\circ} \mathrm{C}$ and was most likely due to the loss of organics (i.e. alkoxy groups). The third drop in mass occurred from the end of the second weight loss $\left(470{ }^{\circ} \mathrm{C}\right)$ until around $600{ }^{\circ} \mathrm{C}$, corresponding to the residual amino groups introduced by APTES during the grafting procedure.

Drug loading was performed in an amoxicillin aqueous solution of $4 \mathrm{mg} \mathrm{ml}^{-1}$. The results shown in Fig. 13A indicate that the drug loading efficiency slightly decreased with an increase of $\mathrm{Mg}$ content in the glass composition. $\mathrm{n}-\mathrm{BG}$ had the highest loading efficiency with $53.68 \%$ of amoxicillin loaded, followed by $\mathrm{n}-\mathrm{BG}^{-\mathrm{Mg}_{3}}$ and $\mathrm{n}-\mathrm{BG}^{-} \mathrm{Mg}_{5}$ with $51.06 \%$ and $49.97 \%$, respectively. Drug loading efficiency is influenced by 4 major parameters: pore size, pore volume, surface area and drug-glass interaction. ${ }^{51,57}$ Pore size should be high enough to permit incorporation of drug molecules into the pore network. In this sense, a minimum ratio of pore size/drug molecular size of 1 is recommended. ${ }^{51}$ In the present study, the average pore size was found to be in the range of 5-6 nm, which is larger than the 

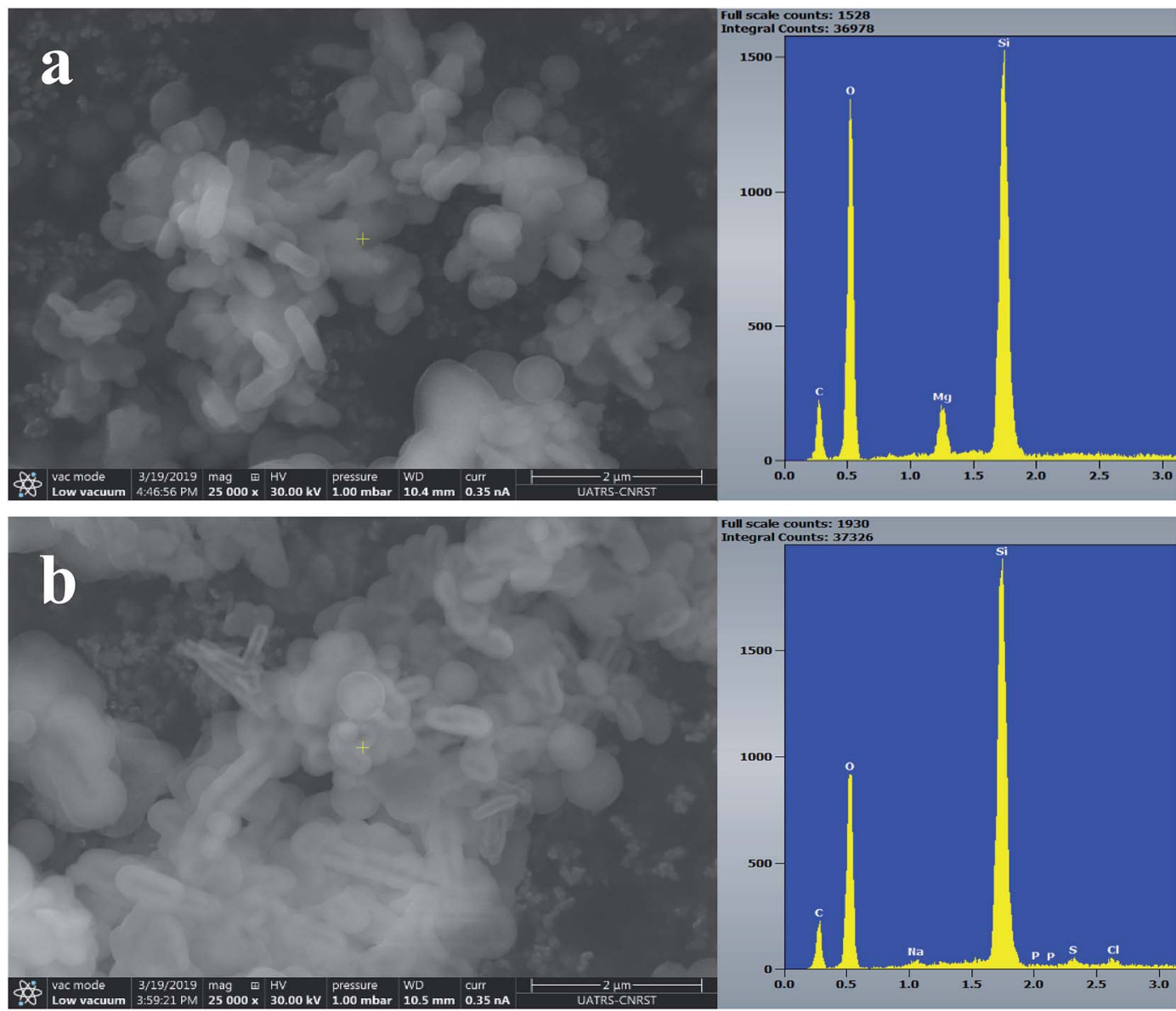

Fig. 9 SEM images of BG-Mg $(a)$ before and (b) after 14 days of immersion in SBF.

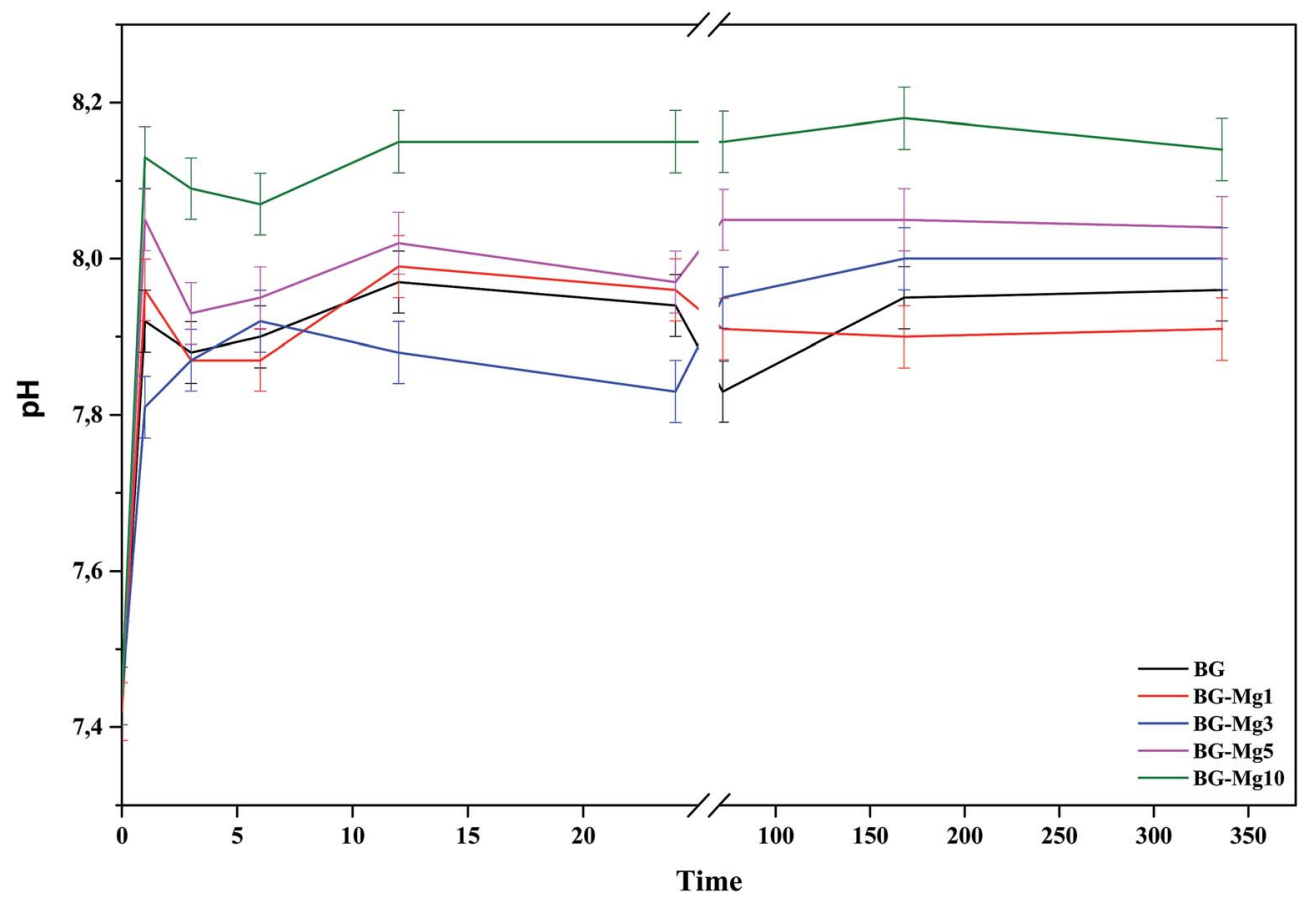

Fig. $10 \mathrm{pH}$ variations during the bioactivity tests in SBF of the BG-Mg samples. 


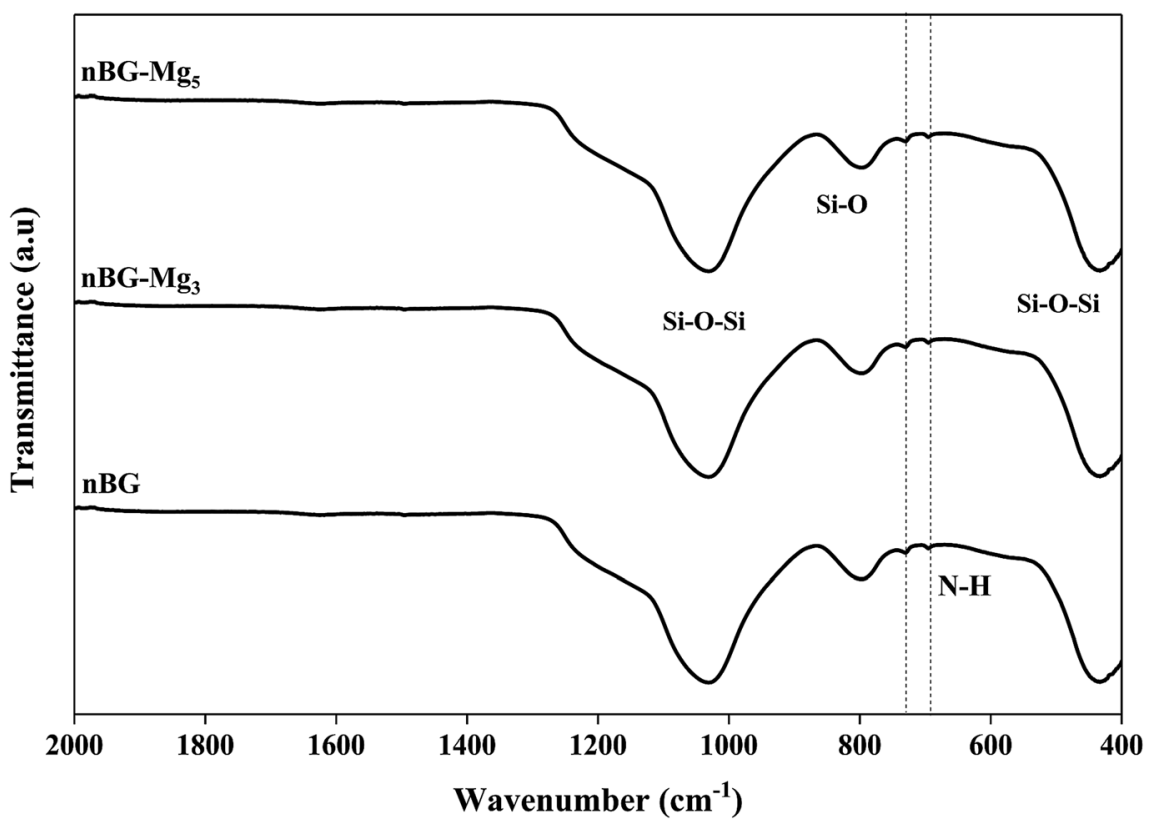

Fig. 11 FTIR spectra of $\mathrm{BG}, \mathrm{BG}-\mathrm{Mg}_{3}$ and $\mathrm{Bg}-\mathrm{Mg}_{5}$ samples after amine functionalization.

molecular length of amoxicillin of $1.1 \mathrm{~nm} .{ }^{57}$ Furthermore, the loading results obtained in the present research are superior to those already reported in the literature of adsorption of amoxicillin into silica based mesoporous matrices. ${ }^{7,8,58}$ One possible explanation for the high amounts of drug loaded into our bioactive glasses is the amino functionalization. Drug-material interaction is one of the major parameters to be considered and the selection of the functionalization group must be done considering the targeted molecule..$^{59}$ It was reported that drug loading could be enhanced with aminopropyl, compared with other groups, ${ }^{58}$ due to its high affinity to the carboxyl groups present in amoxicillin. ${ }^{60}$ In addition to the stronger bond of $\mathrm{COO}^{-}-\mathrm{NH}_{3}{ }^{+}$than that of $\mathrm{COO}^{-}-\mathrm{OH},{ }^{61}$ this would give more sites of interaction and thus more drug molecules to be adsorbed onto the surface of our powders. The slight difference observed in our case is related to the geometry of the pores in each composition. For the virgin glasses, a slightly higher value was recorded compared to the $\mathrm{Mg}$ doped glasses. This is probably due to the cylindrical pore geometry that allowed no more APTES molecules to be loaded between the grafted APTES on the glass surfaces and this relatively enhanced AMX adsorption on the surface. Where pore size was increased (BG- $\mathrm{Mg}_{3}$ and BG-

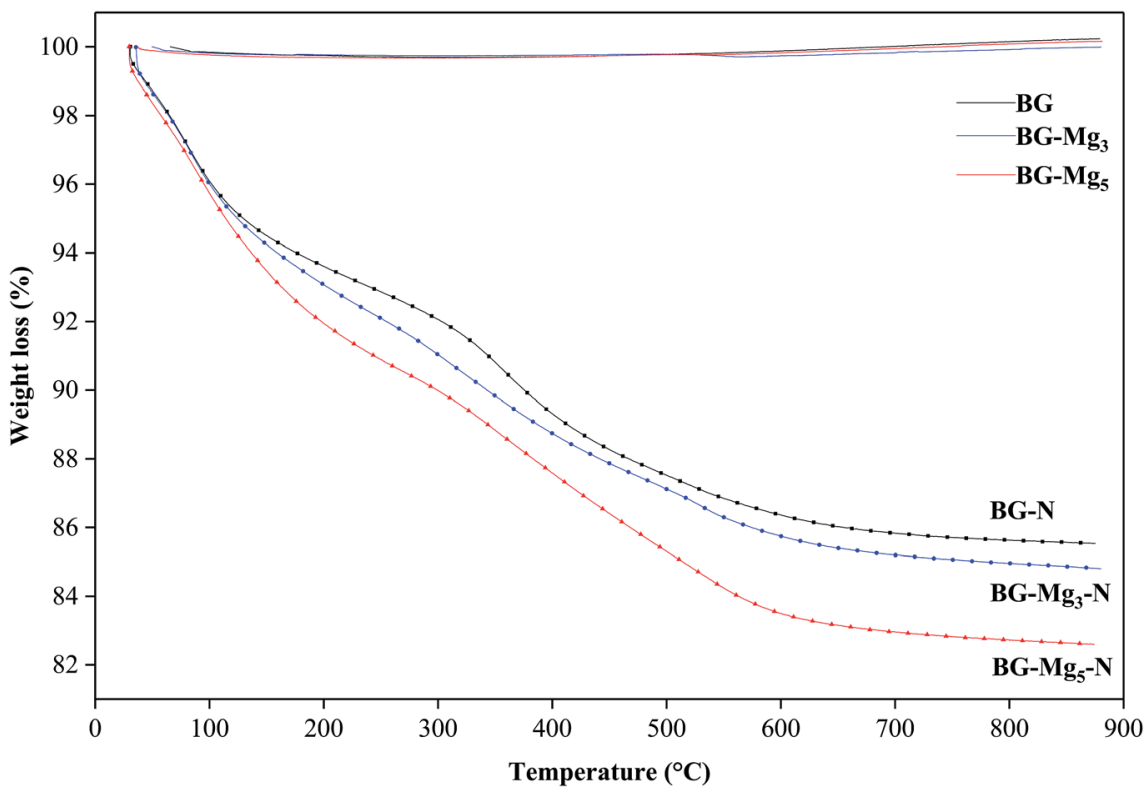

Fig. 12 TGA spectra of bioglasses heat treated at $550^{\circ} \mathrm{C}$ without and with APTES loading. 

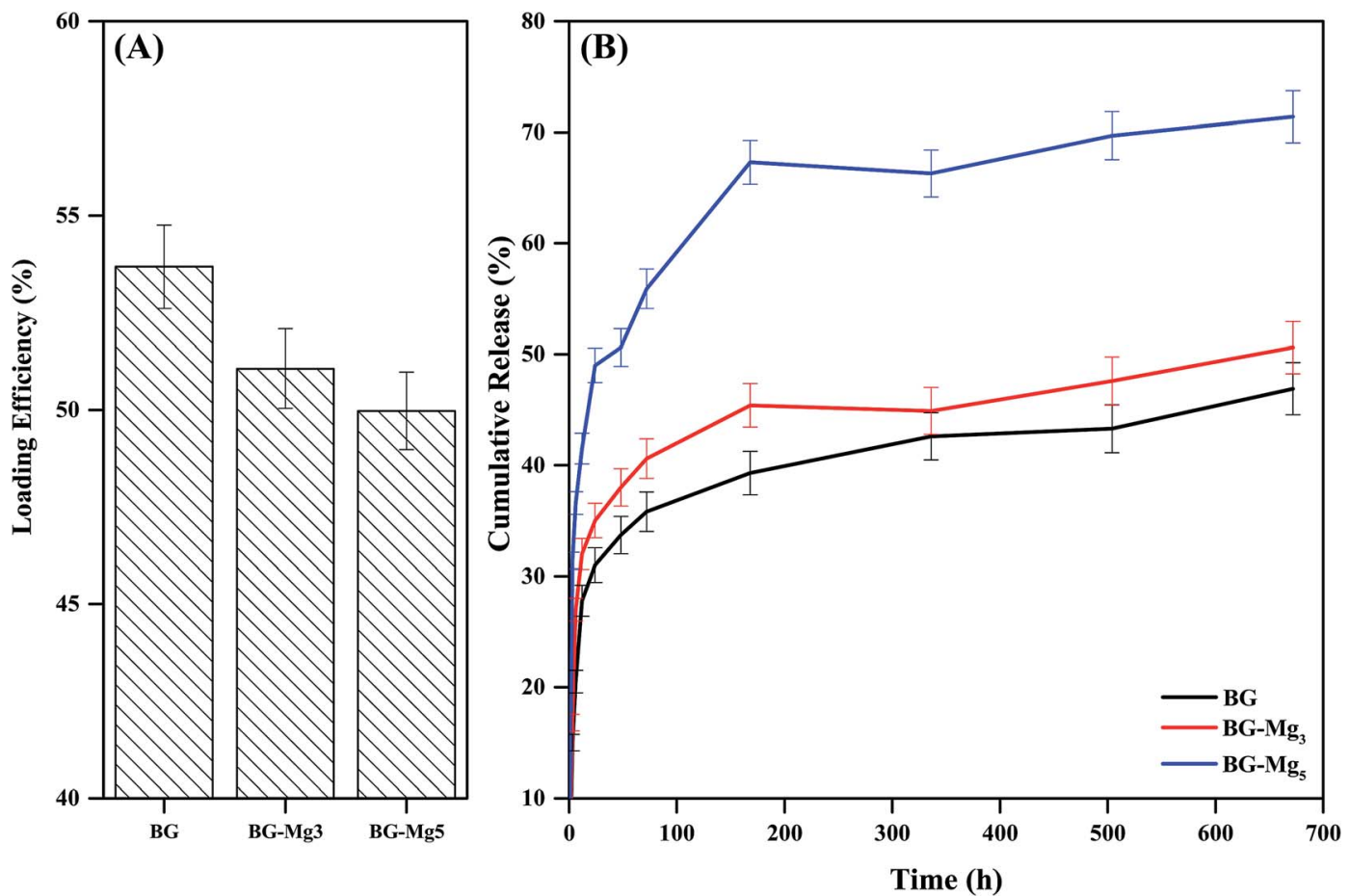

Fig. 13 Loading efficiency (A) of BG, BG-Mg and $\mathrm{BG}-\mathrm{Mg}_{5}$ and their release profiles (B) of amoxicillin in PBS.

$\mathrm{Mg}_{5}$ ), additional APTES molecules could be inserted into the ink bottle shaped pores, which limited the accessibility of the AMX drug molecules for adsorption, and the drug molecules were content to segregate mainly on the surface of the glasses.

Drug release was performed in $\mathrm{PBS}(\mathrm{pH}=7.4)$ at $37^{\circ} \mathrm{C}$ and monitored using UV-spectroscopy. Drug release profiles of amoxicillin loaded n-BG, n-BG- $\mathrm{Mg}_{3}$ and n-BG- $\mathrm{Mg}_{5}$ are shown in Fig. 13B. As can be seen, all release profiles follow a first-order release kinetics, characteristic of a diffusion process. ${ }^{51}$ All three compositions show the same release profile. A quick release ${ }^{62}$ in the first 7 days is followed by a decrease in the rate of release that finally stabilizes. A burst release is desirable, especially where a high concentration of drug is needed; for example, during the first days of implantation in a bone defect, when a high risk of inflammatory responses and infection is present.

The difference between the three profiles lies in the increase of the cumulative amount of drug delivered with increasing magnesium content, which in turn is related to the increase of the specific surface area and the total pore volume of the bioglass powders. This means that the release kinetics of amoxicillin increased although the total amount of drug loaded decreased.

The TGA data after functionalization led us to conclude that the number of amino groups grafted on the surface of the bioactive glasses increased with increasing magnesium content in the glass composition due to the higher textural properties. This would result in the filling of the pores, which suggests that loading of amoxicillin on BG-Mg $\mathrm{Mg}_{5}$ took place primarily on the surface. Our assumption also explains the difference in the drug release kinetics between the three compositions. The surface loaded molecules of amoxicillin would be easily released to the medium, in contrast to the drug molecules trapped inside the pores.

\section{Conclusions}

Mesoporous bioactive glass nanoparticles doped with magnesium were synthetized using a sol-gel method. Primary characterization showed that the nanoparticles had a spherical form and a pore distribution in the meso range $(2-50 \mathrm{~nm})$. The in vitro study of their bioactivity revealed that $\mathrm{Mg}$ incorporation at high molar fractions into the glass network resulted in a fast dissolution rate and solubility of the glass, and a retarding effect on the crystallization of the amorphous Ca-P layer. Further studies of amoxicillin loading and release led to two additional conclusions. Loading efficiency decreased with increasing magnesium content, whereas the release kinetics, which followed a first order profile, increased. The $85 \mathrm{SiO}_{2}-$ $10 \mathrm{CaO}-5 \mathrm{MgO}$ composition showed better results, which was suggested to be due to its higher surface area and pore size. The porosity, surface area and chemical composition of the bioactive glasses played a significant role in controlling the bioactive behavior of the glass samples.

\section{Conflicts of interest}

There are no conflicts to declare.

\section{Acknowledgements}

The authors acknowledge the National Center of Scientific and Technological Research, CNRST (Rabat, Morocco), and the Euromed University of Fes for supporting the present work in the project. 


\section{References}

1 S. Bose, M. Roy and A. Bandyopadhyay, Recent Advances in Bone Tissue Engineering Scaffolds, Trends Biotechnol., 2012, 30, 546-554.

2 H. Oonishi, L. L. Hench, J. Wilson, et al., Comparative Bone Growth Behavior in Granules of Bioceramic Materials of Various Sizes, J. Biomed. Mater. Res., 1999, 44, 31-43.

3 H. Oonishi, S. Kushitani, E. Yasukawa, H. Iwaki, L. L. Hench, J. Wilson, E. Tsuji and T. Sugihara, Particulate Bioglass Compared with Hydroxyapatite as a Bone Graft Substitute, Clin. Orthop. Relat. Res., 1997, 316-325.

4 H. Oonishi, L. L. Hench, J. Wilson, et al., Quantitative Comparison of Bone Growth Behavior in Granules of Bioglass (R), A-W Glass-Ceramic, and Hydroxyapatite, $J$. Biomed. Mater. Res., 2000, 51, 37-46.

5 L. L. Hench, The Story of Bioglass ${ }^{\circledR}$, J. Mater. Sci.: Mater. Med., 2006, 17, 967-978.

6 I. Izquierdo-barba, A. J. Salinas and M. Vallet-Reg, Bioactive Glasses: From Macro to Nano, Int. J. Appl. Glass Sci., 2013, 13, 1-13.

7 R. Li, A. E. Clark and L. L. Hench, An Investigation of Bioactive Glass Powders by Sol-Gel Processing, J. Appl. Biomater., 1991, 2, 231-239.

8 L. L. Hench, Chronology of Bioactive Glass Development and Clinical Applications, New J. Glass Ceram., 2013, 03, 67-73.

9 X. Yan, C. Yu, X. Zhou, et al., Highly Ordered Mesoporous Bioactive Glasses with Superior in Vitro Bone-Forming Bioactivities, Angew. Chem., Int. Ed., 2004, 43, 5980-5984.

10 D. Arcos, D. C. Greenspan and M. Vallet-Regí, A New Quantitative Method to Evaluate the in Vitro Bioactivity of Melt and Sol-Gel-Derived Silicate Glasses, J. Biomed. Mater. Res., Part A, 2003, 65, 344-351.

11 A. Martínez, I. Izquierdo-Barba and M. Vallet-Regí, Bioactivity of a CaO-SiO 2 Binary Glasses System, Chem. Mater., 2000, 12, 3080-3088.

12 C. Vichery and J. Nedelec, Bioactive Glass Nanoparticles: From Synthesis to Materials Design for Biomedical Applications, Materials, 2016, 14, 1-17.

13 K. Zheng and A. R. Boccaccini, Sol-Gel Processing of Bioactive Glass Nanoparticles: A Review, Adv. Colloid Interface Sci., 2017, 249, 363-373.

14 A. Lukowiak, J. Lao, J. Lacroix, et al., Bioactive Glass Nanoparticles Obtained through Sol-gel Chemistry, Chem. Commun., 2013, 49, 6620.

15 M. Erol, A. Özyuguran and Ö. Çelebican, Synthesis, Characterization, and in Vitro Bioactivity of Sol-Gel-Derived $\mathrm{Zn}, \mathrm{Mg}$, and $\mathrm{Zn}-\mathrm{Mg}$ Co-Doped Bioactive Glasses, Chem. Eng. Technol., 2010, 33, 1066-1074.

$16 \mathrm{H}$. Zhu, C. Hu, F. Zhang, et al., Preparation and Antibacterial Property of Silver-Containing Mesoporous 58S Bioactive Glass, Mater. Sci. Eng., C, 2014, 42, 22-30.

17 L. A. Haro Durand, G. E. Vargas, N. M. Romero, et al., Angiogenic Effects of Ionic Dissolution Products Released from a Boron-Doped 45S5 Bioactive Glass, J. Mater. Chem. $B, 2015,3,1142-1148$.
18 M. Dermience, G. Lognay and P. Goyens, Effects of Thirty Elements on Bone Metabolism, J. Trace Elem. Med. Biol., 2015, 32, 86-106.

19 A. Hartwig, Role of Magnesium in Genomic Stability, Mutat. Res., Fundam. Mol. Mech. Mutagen., 2001, 475, 113-121.

20 J. Althoff, P. Quint, E. R. Krefting and H. J. Hohling, Morphological Studies on the Epiphyseal Growth Plate Combined with Biomedical and X-Ray Microprobe Analyses, Histochemistry, 1982, 541-552.

21 A. Hoppe, N. S. Güldal and A. R. Boccaccini, A Review of the Biological Response to Ionic Dissolution Products from Bioactive Glasses and Glass-Ceramics, Biomaterials, 2011, 32, 2757-2774.

22 M. Diba, F. Tapia, A. R. Boccaccini, et al., MagnesiumContaining Bioactive Glasses for Biomedical Applications, Int. J. Appl. Glass Sci., 2012, 3, 221-253.

23 E. Dietrich, H. Oudadesse, A. Lucas-Girot, et al., In Vitro Bioactivity of Melt-Derived Glass 46S6 Doped with Magnesium, J. Biomed. Mater. Res., Part A, 2009, 88, 10871096.

24 P. I. I. Riti, A. Vulpoi, O. Ponta, et al., The Effect of Synthesis Route and Magnesium Addition on Structure and Bioactivity of Sol-Gel Derived Calcium-Silicate Glasses, Ceram. Int., 2014, 40, 14741-14748.

25 T.-H. H. Kim, R. K. Singh, M. S. Kang, et al., Gene Delivery Nanocarriers of Bioactive Glass with Unique Potential to Load BMP2 Plasmid DNA and to Internalize into Mesenchymal Stem Cells for Osteogenesis and Bone Regeneration, Nanoscale, 2016, 8, 8300-8311.

26 J. Lee, M. Kang, C. Mahapatra, et al., Effect of Aminated Mesoporous Bioactive Glass Nanoparticles on the Differentiation of Dental Pulp Stem Cells, PLoS One, 2016, 11(3), 1-22.

27 Determination of the Specific Surface Area of Solids by Gas Adsorption - BET Method (ISO 9277:2010(E)), p. 30.

28 E. P. Barrett, L. G. Joyner and P. P. Halenda, The Determination of Pore Volume and Area Distributions in Porous Substances. I. Computations from Nitrogen Isotherms, J. Am. Chem. Soc., 1951, 73, 373-380.

29 T. Kokubo, H. Kushitani, S. Sakka, et al., Solutions Able to Reproduce in Vivo Surface-structure Changes in Bioactive Glass-ceramic A-W3, J. Biomed. Mater. Res., 1990, 24, 721734.

30 X. Wang, G. Wang and Y. Zhang, Research on the Biological Activity and Doxorubicin Release Behavior in Vitro of Mesoporous Bioactive $\mathrm{SiO}_{2}-\mathrm{CaO}-\mathrm{P}_{2} \mathrm{O}_{5}$ glass Nanospheres, Appl. Surf. Sci., 2017, 419, 531-539.

31 C. R. R. Mariappan and N. Ranga, Influence of Silver on the Structure, Dielectric and Antibacterial Effect of Silver Doped Bioglass-Ceramic Nanoparticles, Ceram. Int., 2017, 43, 21962201.

32 A. El-Fiqi, T.-H. Kim, M. Kim, et al., Capacity of Mesoporous Bioactive Glass Nanoparticles to Deliver Therapeutic Molecules, Nanoscale, 2012, 4, 7475.

33 J. Ma, C. Z. Chen, D. G. Wang, et al., Synthesis, Characterization and in Vitro Bioactivity of Magnesium- 
Doped Sol-Gel Glass and Glass-Ceramics, Ceram. Int., 2011, 37, 1637-1644.

34 I. Izquierdo-Barba, A. J. Salinas and M. Vallet-Regí, In Vitro Calcium Phosphate Layer Formation on Sol-Gel Glasses of the $\mathrm{CaO}-\mathrm{SiO}_{2}$ System, J. Biomed. Mater. Res., 1999, 47, 243250.

35 S. Labbaf, O. Tsigkou, K. H. Müller, et al., Spherical Bioactive Glass Particles and Their Interaction with Human Mesenchymal Stem Cells in Vitro, Biomaterials, 2011, 32, 1010-1018.

36 D. Arcos, M. Vila, A. López-Noriega, et al., Mesoporous Bioactive Glasses: Mechanical Reinforcement by Means of a Biomimetic Process, Acta Biomater., 2011, 7, 2952-2959.

37 A. Chrissanthopoulos, N. Bouropoulos and S. N. Yannopoulos, Vibrational Spectroscopic and Computational Studies of Sol-Gel Derived $\mathrm{CaO}-\mathrm{MgO}-\mathrm{SiO}_{2}$ binary and Ternary Bioactive Glasses, Vib. Spectrosc., 2008, 48, 118-125.

38 V. FitzGerald, R. A. Martin, J. R. Jones, et al., Bioactive Glass Sol-Gel Foam Scaffolds: Evolution of Nanoporosity during Processing and in Situ Monitoring of Apatite Layer Formation Using Small- and Wide-Angle X-Ray Scattering, J. Biomed. Mater. Res., Part A, 2009, 91, 76-83.

39 S. Lin, C. Ionescu, K. J. Pike, et al., Nanostructure Evolution and Calcium Distribution in Sol-Gel Derived Bioactive Glass, J. Mater. Chem., 2009, 19, 1276-1282.

40 P. G. Galliano, J. M. P. López, E. L. Varetti, et al., Analysis by Nuclear Magnetic Resonance and Raman Spectroscopies of the Structure of Bioactive Alkaline-Earth Silicophosphate Glasses, Mater. Res. Bull., 1994, 29, 1297-1306.

41 A. Pedone, G. Malavasi and M. C. Menziani, Computational Insight into the Effect of $\mathrm{CaO} / \mathrm{MgO}$ Substitution on the Structural Properties of Phospho-Silicate Bioactive Glasses, J. Phys. Chem. C, 2009, 113, 15723-15730.

42 M. Thommes, K. Kaneko, A. V. Neimark, et al., Physisorption of Gases, with Special Reference to the Evaluation of Surface Area and Pore Size Distribution (IUPAC Technical Report), Pure Appl. Chem., 2015, 87, 1051-1069.

43 X. Li, X. Wang, D. He, et al., Synthesis and Characterization of Mesoporous CaO-MO-SiO ${ }_{2}-\mathrm{P}_{2} \mathrm{O}_{5}(\mathrm{M}=\mathrm{Mg}, \mathrm{Zn}, \mathrm{Cu})$ Bioactive Glasses/Composites, J. Mater. Chem., 2008, 18, 4103.

44 A. L. B. Maçon, T. B. Kim, E. M. Valliant, et al., A Unified in Vitro Evaluation for Apatite-Forming Ability of Bioactive Glasses and Their Variants, J. Mater. Sci.: Mater. Med., 2015, 26, 1-10.

45 S. Jianga, Y. Zhang, Y. Shu, Z. Wu, W. Cao and W. Huang, Amino-Functionalized Mesoporous Bioactive Glass for Drug Delivery, Biomed. Mater., 2017, 0-18, BMM-101765.

46 C. Y. Huang, T. H. Huang, C. T. Kao, et al., Mesoporous Calcium Silicate Nanoparticles with Drug Delivery and Odontogenesis Properties, J. Endod., 2017, 43, 69-76.

47 A. Saboori, M. Rabiee, F. Moztarzadeh, et al., Synthesis, Characterization and in Vitro Bioactivity of Sol-Gel-Derived
$\mathrm{SiO}_{2}-\mathrm{CaO}-\mathrm{P}_{2} \mathrm{O}_{5}-\mathrm{MgO}$ Bioglass, Mater. Sci. Eng., C, 2009, 29, 335-340.

48 J. Ma, C. Z. Chen, D. G. Wang, et al., Effect of Magnesia on the Degradability and Bioactivity of Sol-Gel Derived $\mathrm{SiO}_{2}$ CaO-MgO- $\mathrm{P}_{2} \mathrm{O}_{5}$ system Glasses, Colloids Surf., B, 2010, 81, 87-95.

49 A. Balamurugan, G. Balossier, J. Michel, et al., Sol Gel Derived $\mathrm{SiO}_{2}-\mathrm{CaO}-\mathrm{MgO}-\mathrm{P}_{2} \mathrm{O}_{5}$ Bioglass System-Preparation Andin Vitro Characterization, J. Biomed. Mater. Res., Part B, 2007, 83B, 546-553.

50 J. Soulié, J. M. Nedelec and E. Jallot, Influence of Mg Doping on the Early Steps of Physico-Chemical Reactivity of Sol-Gel Derived Bioactive Glasses in Biological Medium, Phys. Chem. Chem. Phys., 2009, 11, 10473-10483.

51 M. Vallet-Regí, F. Balas and D. Arcos, Mesoporous Materials for Drug Delivery, Angew. Chem., Int. Ed., 2007, 46, 75487558.

52 J. Massera, L. Hupa and M. Hupa, Influence of the Partial Substitution of $\mathrm{CaO}$ with $\mathrm{MgO}$ on the Thermal Properties and in Vitro Reactivity of the Bioactive Glass S53P4, J. NonCryst. Solids, 2012, 358, 2701-2707.

53 S. V. Dorozhkin, Calcium Orthophosphates in Dentistry, J. Mater. Sci.: Mater. Med., 2013, 24, 1335-1363.

54 M. Bricha, Y. Belmamouni, E. M. Essassi, et al., Hydrothermal Synthesis and Appraisal of Mg-Doped Hydroxyapatite Nanopowders, J. Biomater. Tissue Eng., 2013, 3, 570-580.

55 A. Doostmohammadi, A. Monshi, R. Salehi, et al., Bioactive Glass Nanoparticles with Negative Zeta Potential, Ceram. Int., 2011, 37, 2311-2316.

56 F. Sevimli and A. Yilmaz, Surface Functionalization of SBA15 Particles for Amoxicillin Delivery, Microporous Mesoporous Mater., 2012, 158, 281-291.

57 M. Vallet-Regi, F. Balas, M. Colilla, et al., Drug Confinement and Delivery in Ceramic Implants, Drug Metab. Lett., 2007, 1, 37-40.

58 M. Vallet-Regí, J. C. Doadrio, A. L. Doadrio, et al., Hexagonal Ordered Mesoporous Material as a Matrix for the Controlled Release of Amoxicillin, Solid State Ionics, 2004, 172, 435-439.

59 M. Colilla and M. Vallet-Reg1, Inorganic and Hybrid Controlled Release Systems, Ordered Mesoporous Silica Materials, 2011, pp. 497-514.

60 F. Balas, M. Manzano, P. Horcajada, et al., Confinement and Controlled Release of Bisphosphonates on Ordered Mesoporous Silica-Based Materials, J. Am. Chem. Soc., 2006, 128, 8116-8117.

61 A. Szegedi, M. Popova, I. Goshev, et al., Effect of Amine Functionalization of Spherical MCM-41 and SBA-15 on Controlled Drug Release, J. Solid State Chem., 2011, 184, 1201-1207.

62 S. Wang, Ordered Mesoporous Materials for Drug Delivery, Microporous Mesoporous Mater., 2009, 117, 1-9. 